This item is the archived peer-reviewed author-version of:

Trust in the aftermath of genocide : insights from Rwandan life histories

\title{
Reference:
}

Ingelaere Bert, Verpoorten Marijke.- Trust in the aftermath of genocide : insights from Rw andan life histories

Journal of peace research - ISSN 0022-3433 - London, Sage publications Itd, 2020, , 0022343319899136

Full text (Publisher's DOI): https://doi.org/10.1177/0022343319899136

To cite this reference: https://hdl.handle.net/10067/1684580151162165141 


\title{
Journal of Peace Research
}

First Published April 27, 2020

https://doi.org/10.1177\%2F0022343319899136

\section{Trust in the aftermath of genocide: insights from Rwandan life histories}

\author{
Bert Ingelaere \\ Assistant Professor. IOB, University of Antwerp \\ bert.ingelaere@uantwerp.be \\ Marijke Verpoorten \\ Associate Professor. IOB, University of Antwerp \\ marijke.verpoorten@uantwerp.be
}

\begin{abstract}
Acknowledgements. We received much appreciated comments, at times on very preliminary versions of this paper, from Johan Bastiaensen, Tom de Herdt, Joachim de Weerdt, Siegfried de Witte, Stathis Kalyvas, Filip Reyntjens, Andrea Ruggeri, Pieter Serneels, Ervin Staub, and Elisabeth Wood. We also benefited from useful comments from participants at seminars, conferences and workshops in New Haven (Yale University, OCV), Amherst (University of Massachusetts, The Psychology of Peace and Violence Program), London (LSE, ASEN), Newark (Rutgers University, Center for the Study of Genocide and Human Rights), Warwick (NEPS conference), Barcelona (ENCoRE workshop), Antwerp (IOB), Leuven (LICOS-KULeuven), East Anglia (CBESS), Atlanta (ISA) and Amsterdam (NIOD). Nik Stoop helped compiling a map with our research locations. All errors remain ours. This research was funded by FWO (application grant numbers 1522715N, 12A2214N and 1505415N) and IOB research grants. The first author benefited from a stay as visiting postdoctoral in the Program on Order, Conflict and Violence (OCV), Yale University.
\end{abstract}




\begin{abstract}
We study changes in inter- and intra-ethnic trust in Rwanda. We focus on the impact of the 1994 genocide against Tutsi, which is a case of group-selective violence marked by a clear perpetratorand victim-group as well as within-group variation with respect to exposure to violence. In our empirical analysis, we rely on more than 400 individual life histories in which intra- and interethnic trust were systematically ranked for all life history years. Overall, we find that, while intraethnic trust remains largely unchanged, inter-ethnic trust decreases with the onset of violence and sharply so for those targeted in the genocide. Inter-ethnic trust gradually recovers over time. Only a subset of the victim-group, namely those with the highest probability of individual physical exposure to violence, portray signs of continued outgroup mistrust, 17 years after the genocide. Our results suggest that taking into account the element of time, establishing a fine-grained differentiation of the relevant in- and outgroups in the conflict, as well as identifying the level of exposure to violence, are necessary steps to better understand the impact of political violence on trust. Regarding theory, our findings further qualify what is known about the two-fold theoretical foundation of trust relationships, namely that changes in interpersonal trust reside in altered personal predispositions due to traumatic experiences and/or evolving experiences of trustworthiness in social interaction.
\end{abstract}




\section{Introduction}

'I don't know where the trust comes from but I feel it in my heart.' (Hutu, neither accused nor convicted for genocide crimes, 55 years, female, life history year 2010)

'I can't see what they [Tutsi] carry in their hearts. But I am sure they are not happy with us. They still cultivate ethnic 'ideologies'. They think they are superior'. (Hutu, male, convicted for genocide, 40 years old, life history year 2011.

'I don't trust them. They are all the same. They can kill us like they did in the past.' (Tutsi genocide survivor, 56 years old, female, life history year 2011)

'The Gacaca [community courts dealing with genocide crimes] have clarified things. We have noticed that some of them are innocent, and I did no longer fear the entire group.' (Tutsi returnee, 50 years, female, life history year 2006)

Does the experience of political violence result in changes in inter-ethnic and intra-ethnic trust over time? This question lies at the heart of this article.

Violent conflict kills and maims people, destroys physical capital and reduces human capital. Much less is known about the effects on less tangible factors such as civic and political participation, altruism and collective action, trust and trustworthiness. These factors are often captured under the umbrella term 'informal institutions' and relate to so-called 'prosocial preferences', thus the inclination to behave in the best interest of other individuals (Eisenberg \& Mussen, 1995). As argued by Blattman \& Miguel (2010) and Wood (2008), enhancing our understanding of the impact of wartime violence on these institutional and social processes is key for our understanding of a society's postwar recovery and transformation. Persistent parochial preferences (i.e. geared towards a specific ingroup) may perpetuate intergroup hostilities, thus increasing the risk of conflict re-occurrence. Our focus is on interpersonal trust, which is a distinct prosocial attitude, and one of the strongest predictors of cooperation that positively influences other concrete expressions of prosocial behavior, such as civic engagement and political participation (Brehm \& Rahn, 1997; Sullivan \& Transue, 1999). Trust is also widely credited for reducing economic transaction and improving government functioning, both of which can lift the economy to a higher growth path (Weil, 2009). 
In recent years, a rapidly growing body of studies has measured the impact of political violence on trust (Bellows and Miguel, 2009; Cassar, Grosjean \& Whitt, 2013; De Luca \& Verpoorten, 2015a; Gilligan, Pasquale \& Samii, 2013; Inglehart, Moaddel \& Tessler, 2006; Kunovich and Hodson, 1999; Rohner, Thoenig \& Zilibotti, 2013; Shewfelt, 2009; Traunmüller, Born \& Freitag, 2015; Ward et al., 2009). But, results are not converging. One measurement issue underlying the heterogeneity of results may be the distinction between in- and outgroup. In a meta-analysis, Bauer et al. (2016: 20) conclude that on average there is no effect on trust but that the generality of this finding is not clear as more research is needed on behaviors towards outgroup members. At present, 'there are relatively few studies with the detailed trust questions needed to undertake this analysis'. The number of peace years emerges as a second important factor of heterogeneity. For instance, Rohner, Thoenig \& Zilibotti (2013) show that civil conflict in Uganda reduces survey-based measures of trust, three years after the end of violence. Studying the impact of the same violence, but another four years ahead, De Luca \& Verpoorten (2015a) find a complete recovery of trust. Furthermore, Traunmüller, Born \& Freitag (2015: 24), in a cross-country analysis, find that large initial heterogeneity of the impact of war on trust disappears over time: '[...] eventually time heals the wounds of civil war [...] The precise processes at work, however, are not well understood'. Third and finally, time may not heal all wounds. Studying social trust in Kosovo, Kijewski \& Freitag (2018) find that the negative impact of war is more robust and lasting for individual war experiences than for war exposure measured at the community level. Another recent study, by Blouin \& Mukand (2019) on inter-ethnic trust in Rwanda, reaches inconclusive results and argues that the 'lack of precision could be because there is heterogeneity in the genocide effect by ethnicity.' (Blouin \& Mukand, 2019: 40). Hence, apart from distinguishing between ingroup and outgroup trust, and taking the time dimension into account, it seems needed to make a distinction between (sub)groups of individuals differently exposed to violence.

We take these three dimensions of heterogeneity into account when studying the effects of the 1994 genocide on interpersonal trust in Rwanda. We assume that genocide constitutes an utmost attack on trust, from which it is difficult to recover. Kalyvas (2006: 26) argues that violence has a communicative function and signals the shape of actual or future social interactions. Group-selective violence signals that one does not foresee future social interactions with the targeted population, whereas violence in war aims to shape the behavior of the targeted 
population in light of future social interactions (Straus, 2015: 24). Genocidal violence is a specific form of group-selective violence to the extent that the violence communicates to the victims that the ability of their group to survive and reproduce is to be destroyed. In terms of relations of trust, our case study of genocidal violence is therefore likely a worst-case scenario. In terms of methodology, we rely on the systematic ranking of inter- and intra- ethnic trust throughout life histories of over 400 Rwandan individuals, yielding high-frequency time observations from five years prior to the genocide up to 17 years after, and this for distinct subgroups on both the victim- and the perpetrator- side of the genocidal violence.

With our case study and methodological approach, we make four specific contributions. First, although it has been widely acknowledged that violent conflict likely affects in- and outgroup trust differently, only a few empirical studies on trust have been able to clearly identify in- and outgroup trust (e.g. Inglehart, Moaddel \& Tessler, 2006), among others because standard surveys often do not include the information needed for such identification (for a review see Bauer et al., 2016). In our study, in contrast, we systematically inquired about in- and outgroup trust. Second, whereas a number of studies have shown that time is a factor to take into account (e.g. De Luca \& Verpoorten, 2015a; Traumuller, Born \& Freitag, 2015), our continuous time series on trust pioneer in revealing the recovery path of trust after violence. Third, unlike most studies (an exception is Kijewski \& Freitag, 2018), we can - within our pool of respondents clearly identify the relevant in- and outgroups, and also detect within-group variation in the probability of individual exposure to violence. We will argue that, in the case of the victim group (ethnic Tutsi) this variation is quasi-exogenous, which allows us to contrast the impact of individual- and group-level exposure to genocidal violence. Finally, with the case of Rwanda, we add a hard case to the literature. As explained, genocidal extermination is an utmost attack on trust between members of opposing social groups. If, in this worst case scenario, we find recovery of trust, then it suggests that trust recovery certainly is possible in other cases.

The next section lays out the theoretical framework and associated hypotheses. We then give a brief background to the Rwandan case, followed by an explanation of our data and method. In the penultimate section we present our results. The final section concludes.

\section{Theory and hypotheses}


There are two broad perspectives on the foundations of trust: trust as a personal predisposition and trust as grounded in concrete experiences of trustworthiness in social interactions (Freitag \& Bühlmann, 2009: 787). The latter is the result of an evaluation of the individual's social environment whereas the former is a propensity ascribed by birth or acquired in early life, or later on through traumatic events (van der Kolk, 1996). From these viewpoints on trust, it follows that the evolving nature of trust relations resides in a combination of changing experiences and predispositions. These, in their turn, can be affected by personally lived (traumatic) events (Gobin \& Freyd, 2014) but also by collective experiences and changes in society's infrastructure, including its political institutions or social networks (Wood, 2008).

These perspectives on the foundations of trust have informed theories, in all major social science disciplines as well as evolutionary biology, on the impact of violence on trust relationships. Relying on these theories, we formulate testable hypotheses on the differential impact of violence across the three dimensions highlighted in this study. We start with the common theoretical prediction regarding the short-term effect of violence on outgroup and ingroup trust. We then add the additional distinctions, with respect to the number of peace years elapsed, and individual-level exposure to violence.

\section{Ingroup vs outgroup trust}

In the theoretical literature on ethnicity, a consensus emerged that political violence with an ethnic character creates or reconfigures bounded ethnic groups by increasing the sense of belonging to a distinct group and facilitating the differentiation from outgroup members (Brubaker, 2006: 19; Wimmer, 2012: 70-72). And, it is commonly assumed that the immediate impact of violence on outgroup trust is negative (e.g. Collier et al. 2003). The theoretical underpinning of this assumption has two pillars. First, the negative effect could result from updated expectations about the potential malevolent actions of 'the others' (Cook, Hardin \& Levi, 2005; De Luca \& Verpoorten, 2015a). Second, aside from being triggered by a rational calculus, the decrease in outgroup trust may result from a psychological predisposition that is rooted in an evolutionary process. In particular, throughout human history and the associated cultural and genetic evolution, intergroup competition has given way to parochial preferences that breed 
ingroup cohesion and cooperation at the expense of prosocial preferences towards the outgroup, thereby enhancing a group's success of survival (Boyd \& Richerson, 1985; Bowles, 2006).

In line with this theory on 'parochial preferences', the effect of violence on ingroup trust, on the other hand, is assumed to be positive (Gneezy \& Fezzler, 2011). Increased ingroup trust may also be in line with a rational calculus since violence and its destruction of human and physical capital may increase the value of social capital, and thus promote ingroup trust, as its close correlate (as argued in Bauer et al., 2016, and Gilligan, Pasquale \& Samii, 2013).

Based on these existing theories, we hypothesize:

H1a. Outgroup trust decreases with the onset of violence

H1b. Ingroup trust increases with the onset of violence

\section{Peace duration}

Our second distinction relates to the time scale of the impact of violence on trust. The theoretical observation that interpersonal trust partly resides in actual experiences of social relations suggests that improvement over time is possible. If there is openness to new information about the evolving nature of social interactions - referred to as 'unfreezing' (Bar-Tal \& Halperin, 2013: 8), individuals may gradually update their beliefs and expectations about 'the other', bringing about a recovery in outgroup trust. To have an impact, the new information should be perceived of high value and credibility, such that it can effectively challenge the message that was sent by violence (Bar-Tal \& Halperin, 2013). Conditional on such unfreezing, the passing of time allows for events and policies to bring about such updates. These events and policies can range from truthseeking activities, apologies, accountability measures to everyday processes that inform about the nature and quality of interpersonal and intergroup relationships (Allport, 1954), or just the passing of time that separates the harmed person from the harmful event (Wohl \& McGrath, 2007; Traunmüller, Born \& Freitag, 2015). Conversely, in the case of ingroup trust, a normalization of events and social relations may also lead to a return of ingroup attitudes to preconflict levels (Gneezy \& Fezzler, 2011).

We test the following hypotheses: 
H 2a. Over time, outgroup trust returns to pre-violence levels.

H 2b. Over time, ingroup trust returns to pre-violence levels.

\section{Individual exposure to violence}

According to psychologists, personal predispositions are innate but can also be affected by major life events. In particular, experience with traumatic events can set in motion a series of behavioral and cognitive responses which determine how the events come to be remembered and interpreted. At the two extremes lay two diametrically opposed outcomes: Post-Traumatic Stress Disorder (PTSD) and Post-Traumatic Growth (PTG) (Ehlers \& Clark, 2000, Gobin \& Freyd, 2014, Tedeshi \& Calhoun, 2004). PTSD is an anxiety disorder that creates a persistent sense of current threat and avoidance, perpetuating the overgeneralized fear. PTG, on the other hand, is a label used to describe a positive development, surpassing 'what was present before the struggle with crises occurred' (Tedeshi \& Calhoun, 2004: 4). In the conflict literature, referral has been made to PTSD as a persistent negative outcome of experiencing or witnessing violence (Scholte et al., 2004; Steel et al., 2002). Other conflict studies have pointed to PTG as a driver of persistent positive effects of violence on prosocial attitudes (e.g. Bauer et al., 2016; Traunmüller, Born \& Freitag, 2015). Although diametrically opposed, both processes involve a change in personal predispositions, and are thus likely to have a persistent impact on trust.

Following the theoretical literature, we hypothesize that, if the anxiety disorder PTSD prevails, individuals most exposed to violence exhibit persistently lower trust:

H 3. The post-violence trust trajectories of those individually exposed to violence stay below the trajectories of those that were not/less exposed at the individual level.

If instead PTG is dominant, the following competing hypothesis is expected to hold:

H 3'. The post-violence trust trajectories of those individually exposed to violence rise above the trajectories of those that were not/less exposed at the individual level.

The heterogeneity of PTSD and PTG, in terms of in- and outgroup attitudes, and across perpetrators and victims, remains relatively unexplored. In the case of PTSD, the overgeneralized fear may be truly general, or restricted to those associated with 'the other(s)' in the traumatic 
event (Ehlers \& Clark, 2000). Regarding PTG, Bauer et al. (2016: 27) write: 'Such changes need not be parochial in nature; the existing literature in this area is silent on this point.' Whereas PTSD and PTG are generally examined in relation to victims of violence, a small but growing body of literature relates these outcomes also to the act of killing (Macnair 2002a; 2002b), and calls are made to further develop this domain of study, both theoretically and empirically (Blackie, Hitchcott \& Joseph, 2017; Marotta-Walters, Choi \& Shaine, 2015). With respect to these two relatively unexplored heterogeneities of PTSD and PTG, our analysis will be more exploratory, rather than geared towards the testing of specific hypotheses.

\section{Background}

Rwanda was colonized by Germany but later passed on to Belgium as a United Nations Trust Territory. In line with the anthropological ideas of the time, the Belgians believed in the classification of superior and inferior races, and judged the Tutsi minority (14\%) to be more fit to rule than the Hutu majority $(85 \%)$. Identity became racialized and institutionalized, for example, through the introduction of the ethnic identity card. A spirit of independence made its way through Africa and touched Rwanda at the end of the 1950s. In a wave of events between 1959 and 1962 local Tutsi rulers were ousted from their communities and replaced through elections by 'burgomasters', predominantly of Hutu origin (Prunier 1995: 41-54). Grégoire Kayibanda, a Hutu, became the first president of Rwanda. These events were accompanied by violence against the Tutsi rulers and their families, and Tutsi sought refuge in neighboring countries.

The descendants of these refugees formed the backbone of the Rwandan Patriotic Front (RPF) and its military wing that attacked Rwanda in October 1990, seeking an armed return to their country. ${ }^{1}$ It led to a period of hostilities and negotiations with the Rwandan government until a peace agreement was reached in 1993. But, in April 1994, the plane carrying the Hutu President Habyarimana was shot down. This signaled the start of a campaign of genocidal violence against the Tutsi minority. Tutsi living inside Rwanda were stigmatized as 'enemies from within,' 'cockroaches' and 'accomplices' of the RPF (Des Forges, 1999: 76-78; Straus,

\footnotetext{
${ }^{1}$ The attack occurred at a time of economic distress, when the population was fighting an uphill battle against declining food production (Verpoorten, 2012a) and the elite was struggling to maintain its neo-patrimonial political system (Prunier, 1995).
} 
2006). They were indiscriminately targeted and ordered to be killed. The civil war between the RPF and the Rwandan government, which had been halted the year before, restarted and intensified.

By the end of June 1994, the RPF had taken control of the country and had put an end to the genocide against Tutsi. Relative order was established, although the RPF condoned or engaged in reprisal killings and massacres of Hutu civilians (Des Forges, 1999: 530-560). Till the late nineties, the defeated 'old regime' security forces and militias who had fled across the border to DR Congo engaged in insurgencies in the North-West of Rwanda, that were answered with brutal counter-insurgency activities by the security forces of the new government (African Rights, 1998; Verpoorten, 2012b). In terms of post-genocide processes and events, the violence led to the imprisonment of more than 100,000 Hutu for crimes related to the genocide against Tutsi (Tertsakian, 2008) and 1,958,634 cases of alleged participation in the genocide, processed by 11,000 community courts (Gacaca) between 2005 and 2012 (Ingelaere, 2016). Furthermore, the externally displaced remained several years in camps across the border, with most of them only resettling in Rwanda in the course of 1997-1998 (UNHCR, 2000). Finally, Rwandan Tutsi who lived in exile prior to the genocide also returned to their country of origin.

These processes re-casted individuals into distinct subgroups (Ingelaere, 2010). The recategorizations of Hutus mainly depended on judicial operations, and shifted over time, from imprisonment towards accusation of alleged participation, and finally towards actual conviction for genocide crimes. In our analysis, and as further explained below, we will use the distinction between Hutus convicted for participation in the genocide and those who were not convicted. Among Tutsis, the most important distinction is that between so-called 'Tutsi survivors', who were living in Rwanda at the time of the genocide, and so-called 'Tutsi returnees', that is the Tutsi - or their descendants - who fled Rwanda in the years and decades following 1959, and returned from exile after the RPF seized power. While the genocide against Tutsi indiscriminately targeted all Tutsi, its large-scale execution took place inside the Rwandan borders. The death toll among Tutsi inside Rwanda is estimated to lie in between 512,000 and 662,000, which corresponds to 65\% and 80\% of the Tutsi population living in Rwanda in 1994 
(Verpoorten, 2005; 2014). ${ }^{2}$ Tutsi returnees were not physically exposed to the Rwandan genocide, simply because they were not living in Rwanda in 1994 when mass genocidal violence occurred. The different exposure across returnees and survivors is supported by a spatial analysis of excess mortality across Rwanda's 1500 administrative sectors (Verpoorten, 2012b). Comparing sector-level excess mortality as calculated from the full 2002 population census, it is shown that sectors inhabited by a large share of Tutsi returnees (survivors) are characterized by much lower (higher) than average excess mortality.

\section{Data \& Methods}

To test our hypotheses, we rely on data derived from life histories. The first author on this article designed the life history approach and performed the fieldwork ${ }^{3}$, collecting 471 life histories in a first round (January-April 2007) and 412 stories of the same respondents in a follow-up round (January and June 2011). ${ }^{4}$ Those not traced in 2011 - e.g. due to imprisonment at that time - were revisited in 2015. In the second wave, the respondents were not asked to continue their life history where they left it in 2007, but to start in 2000. As a result, we have an overlapping period of life history years, 2000-2007, which allows us to assess recall bias.

The sample of respondents was stratified geographically across seven communities in four different provinces. Research locations, indicated in Figure 1 and described in Supplementary Appendix A1, were chosen based on the idea of attaining maximum variance in conflict and post-conflict experiences. To select individuals, lists were compiled with the names

\footnotetext{
${ }^{2}$ The death toll among Tutsi is contested. For a discussion see Verpoorten (2014). The death toll among Hutu is likely to be high in absolute numbers, but it is much smaller as a proportion of the Hutu population and includes a large share of indirect deaths, among others as a result of the massive refugee crisis (Des Forges, 1999; Verpoorten, 2012).

${ }^{3}$ The author trained and supervised a team of 10 local collaborators, was continuously present in the field during the data collection (in total 16 months), was personally present during approximately one third of the interviews and verified all of the collected material on a daily basis.

${ }^{4}$ Ethical review was conducted and granted by the University of Antwerp's Ethics Committee for the Social Sciences and Humanities (file nr. SHW_14_32_04 and nr. SHW 18_75), permissions to conduct fieldwork were granted by several Rwandan ministries and institutions (MINALOC \& MIJESPO \& MINEDUC \& SNJG \& President Office) More information on fieldwork, method and data of the larger project is available in Ingelaere (2013).
} 
of all household heads in each location. Subsequently households were selected through a random sampling scheme, by the prevalent ethnic subgroups in the location. Since the use of ethnic markers is strictly policed by the post-genocide regime ${ }^{5}$, the sampling of respondents was based on alternative markers - presented in Supplementary Appendix A2 - that underlie ethnic categories and that are commonly used by Rwandans to identify themselves and others.

For the analysis, we make a distinction on each side of the ethnic divide. Tutsi are divided into 'survivors' and 'returnees'. These groups differ in terms of individual exposure to the 1994 genocide, because the survivors were present on Rwandan soil in 1994, while the returnees were not. On the side of Hutu, we differentiate between those that were convicted for participation in the genocide and those that were not. As further explained in Supplementary Appendix A2, the 'convicted' include those who were found guilty for committing violence against humans in the gacaca trials (excluding those only convicted for property crimes). They are therefore more likely than the non-convicted Hutu to have been individually exposed to violence (as a perpetrator). All respondents were over 30 years old, since they needed to have lived through the period of mass violence consciously in order to rank trust by recall for that period. Table I gives an overview of the number of respondents and the (sub)group they belong to: the 2007 sample included 154 Tutsi (101 genocide survivors and 53 returnees) and 317 Hutu (245 non-convicted and 72 convicted for participation in the genocide).

\section{--Figure 1 about here--}

\section{--Table I about here--}

To allow for a quantitative analysis, the life history interviews were structured by a ranking exercise in which the respondents were asked to systematically comment on inter- and intra-ethnic trust and rank it on a scale of -5 to +5 for every year in their life story. Figure 2 shows the visual aid used for the ranking exercise. The respondents were asked to situate themselves on the 'ladder', through time, starting with the year of the interview, by answering the question: 'Currently, on what step [on the ladder] do you situate your experience of trust towards members of the other (your own) ethnic group?' Subsequently a move back in time was made to

\footnotetext{
${ }^{5}$ Although ethnicity is a sensitive topic in contemporary Rwanda, Rwandans do speak about ethnicity in private settings. All interviews were conducted in the house of the respondent without onlookers present in order to avoid reservation in response.
} 
the year of marriage or the first year of adult life (if single), repeating the question for that point. Then, the interviewer moved forward, asking the ranking for each year in between. For example, a female respondent of 36 years old, interviewed in 2007, would first give the ranking in 2007, then for the year she turned 18 (1989), or earlier, e.g. 1987 if she married at 16. Then, all years in between would be ranked consecutively. The findings from the life history narrative were used to help people recall their situation at a certain moment in time. For example, when someone had told us he or she had a firstborn child in 1986, reference would be made to 1986 as 'the year when your first child was born'.

\section{--Figure 2 about here--}

To assure a common understanding of 'trust' by our respondents, we explored in a pilot phase how to best inquire about 'trust'. This inquiry revealed a shared understanding of trust (Icyizere), as being confident in the nature of one's heart, a nature that was said to be signaled and detected in daily life by various behaviors, e.g. attending ceremonies, providing material and mental support, and speaking truthfully (Ingelaere 2016: 147-154). The pilot phase included 50 full life story interviews with 30 Hutu and 20 Tutsi respondents, lasting each in between 7 and 14 hours (spread over several sessions). These interviews were conducted through open-ended questions touching on almost every aspect of the interviewee's life. The subsequent structuring of the interviews allowed a focus on a limited number of salient themes that emerged from the life stories (inter-ethnic trust, intra-ethnic trust, political representation, security and economic situation) and a strongly reduced interview time of 1.5-3.5 hours. However, also in their semistructured form, the interviews gave the respondent room for 'telling' his/her life history. Moreover, in round 2, thus starting from life history year 2000, respondents were asked to explain in their own words the reasons of their end line levels of trust as well as those for the changes in trust throughout their life history years. In total, this resulted in 1241 narratives for inter-ethnic trust, and 797 narratives for intra-ethnic trust. The four quotes at the start of this article are examples of excerpts of such narratives.

Our data could suffer from three common caveats: recall bias, attrition bias, and social desirability bias. To explore whether recall bias is a serious concern or not, we exploit the overlapping recall period of our two interview rounds, 2000-2007. Comparing the sample 
averages of trust over time, as reported in round 1 and round 2, we find that the difference is relatively small (0.23 units for inter-ethnic trust and 0.40 for intra-ethnic trust), reducing concerns of serious recall bias. Supplementary Appendix A3 gives further details across subgroups. In our baseline results, we analyze the rankings for the overlapping period as reported in the first data round, in 2007. In a robustness check we show that, using instead the rankings collected in 2011 for the overlapping period, leaves our conclusions intact. To investigate attrition bias, we compare round 1 trust levels between the drop-outs $(12.5 \%$ of the sample) and the traced respondents. Supplementary Appendix A4 shows that trust levels differ across dropouts and traced respondents, by 0.51 units for inter-ethnic trust and 0.35 units for intra-ethnic trust, on average for the period 1989-2007. In our baseline result, we rely on the life histories of the 412 respondents that could be traced over time; the robustness check reveals that our results remain when using instead the unbalanced panel of 471 respondents. Finally, our self-reported measure

of inter-ethnic trust shares the lack of incentive compatibility with standard survey-based measures. In the absence of incentives for responding truthfully, other motives may take the upper-hand, most importantly social desirability. On the other hand, in our case, the reporting is imbedded in the respondent's life history, imposing a 'consistency constraint', namely the reported levels and changes of trust need to be compatible with other events in the life history and with the narratives regarding trust. While not completely ruling out biases, the use of a calendar approach through which event history data are collected has proven to be more reliable than survey approaches (Belli, Shay \& Stafford, 2001), also in the context of data-collection following traumatic events (Barber et al., 2016).

\section{Results}

\section{Baseline results}

We analyse the life history data across the three dimensions of theoretical and empirical heterogeneity stressed above. We start the analyses from 1989 onwards; this is a natural starting point, as it is the year before the outbreak of the civil war. Figure 3 shows the pathways of interand intra-ethnic trust. Table II presents the levels of inter-ethnic trust and intra-ethnic trust, across four points in time: our baseline year 1989, the genocidal year 1994, and our two data collection years 2007 and 2011 for which the trust levels were reported in current time, not through recall. 
The table also gives the change with respect to the base year 1989. Statistically significant differences are indicated with one or more asterisk.

From Figure 3, it is clear that inter-ethnic trust, as recalled by our respondents, declined already from 1990 onwards, when the RPF attacked Rwanda, and reached a low point in 1994, the year of the genocide against Tutsi. In particular (and as presented in Table II), on our scale of -5 till +5 , inter-ethnic trust declines with 5.63 points in the period $1989-1994$, from +3.92 to 1.71. Thus, in line with Hla, we find a decline of inter-ethnic trust. Intra-ethnic trust - given by the dashed lines - declines to a much lesser extent, with 2.43 points, from +4.28 in 1989 to +1.85 in 1994. This asymmetry across inter-ethnic trust and intra-ethnic trust results in an increased gap between ingroup and outgroup trust, a finding that is indicative of the emergence of polarized group identities. However, unlike hypothesized in Hlb, there is no increase in intra-ethnic trust, on average.

\section{--Figure 3 about here - --Table II about here --}

Is time an important factor in the assessment of interpersonal trust levels? Figure 3 reveals a clear upward trend in inter-ethnic trust from 1994 onward. Compared to the low of -1.71 in 1994, inter-ethnic trust levels in both 2007 and 2011 are much higher at +1.17 and +2.11 , respectively. In 2011, 17 years after the genocide, inter-ethnic trust remains however significantly lower than its 1989 level. Looking at the summary results for intra-ethnic trust, we also find an incomplete recovery from a low in 1994. Thus, while over time, outgroup trust approaches pre-violence levels even in the aftermath of genocidal violence, the return is incomplete. Hence, this finding is only partly in line with $\mathrm{H} 2 \mathrm{a}$, as there is not a complete return to pre-war levels.

Our final distinction relates to the differences in exposure to violence. To explore this dimension, we will distinguish the subgroups with the highest probability of individual exposure, on the side of the perpetrator group as well as the victim group. Before zooming in on the subgroups, we explore trust trajectories at the level of the victim and perpetrator group. Figure 4 contrasts the trajectories for Hutu and Tutsi. Table III and IV present the levels and changes of inter- and intra-ethnic trust, across time and (sub)groups. 
Panel A of Figure 4 shows that the decline of inter-ethnic trust is much larger for Tutsi than for Hutu. In particular, inter-ethnic trust as reported by Tutsi declined by 7.77 points (from +3.29 in 1989 to -4.48 in 1994), while inter-ethnic trust reported by Hutu declined by 4.55 points (from 4.25 in 1989 to -0.30 in 1994). Looking at intra-ethnic trust, we find a trajectory that is largely flat for Tutsi: in between 1989 and 1994 there is an insignificant decrease of just -0.30 points (from +4.21 to +3.91 ). For Hutu, in contrast, intra-ethnic trust considerably declines, with 3.51 points (from +4.31 in 1989 to +0.80 in 1994). These trajectories reveal that the distance between inter-and intra-ethnic trust increases for Hutu as well as for Tutsi, but that this distance and thus the parochial nature of the change in trust is much more pronounced for Tutsi, who were targeted in the group-selective violence. In other words: the differentiation between ingroup and outgroup (trust) remains more salient for those that belong to the group that was targeted to be destroyed.

\section{--Figure 4 about here - --Table III about here -- --Table IV about here --}

Figure 5 contrasts the trust trajectories across Tutsi survivors and Tutsi returnees. Panel A shows that, prior to and during the violence, their inter-ethnic trust trajectories virtually overlap. More precisely (and detailed in Table III), throughout the period 1989-1994, Tutsi survivors accumulated a decline of -7.96 in inter-ethnic trust, landing at -4.49 in the genocidal year 1994 . Very similarly, throughout the same period, inter-ethnic trust as reported by Tutsi returnees decreased by -7.30 , to land at -4.43 in 1994 . Given that returnees were not living in Rwanda at that time and thus not individually exposed to the risk of genocidal violence, this finding indicates that the message of group-destruction was sufficient to bring inter-ethnic trust levels near the bottom of the ranking. The recovery process is, however, very different across the Tutsi subgroups. While returnees report a rather swift and almost complete recovery of inter-ethnic trust (reaching +2.43 in 2011), the recovery for survivors is very incomplete (at +0.14 in 2011). This recovery gap between survivors and returnees is consistent with $H 3$, that the post-violence trust trajectories of those individually exposed to violence stay below the trajectories of those that were not/less exposed at the individual level. Note that, in our assessment of this hypothesis, 
we assume that Tutsi returnees are an appropriate control group for Tutsi survivors. In particular, we assume that-in the absence of individual level exposure to genocidal violence on the part of the survivors- the trust trajectories of Tutsi survivors would be similar to those of the Tutsi returnees. While the overlapping inter-ethnic trust trajectories prior to the violence support this 'parallel trends assumption', we relax it in a regression analysis below, in which we control for potentially confounding factors (age, sex, economic mobility and political representation). Regarding intra-ethnic trust, Panel B of Figure 5 shows a rather flat trajectory, especially so for Tutsi returnees and to a lesser extent for Tutsi survivors (who report a slight, but statistically significant, erosion of intra-ethnic trust over time).

\section{--Figure 5 about here -}

On the side of Hutu, we distinguish between those convicted for violence against humans, and those not. Figure 6 and Table III show that both subgroups start at similar inter-ethnic trust levels in 1989 (4.26 and 4.20), but that the convicted land 2.78 points lower in 1994 than the nonconvicted (at -2.52 vs 0.27 ). It is impossible to say whether the 1994 low point for the convicted is an outcome of committing genocidal violence, or a cause of it (with the most mistrusting Hutu participating in the genocide). Either way, the findings of the within-Hutu comparison are not in line with H3: in the period 1994-2002, we observe an almost parallel recovery path across convicted and non-convicted, and from 2003 onwards (the time at which many prisoners were released), the recovery of inter-ethnic trust accelerates for the convicted leading to a reduction of the inter-ethnic trust gap with the non-convicted (from 2.78 in 1994 to 1.20 units in 2011). Finally, looking at intra-ethnic trust, we find a much stronger 1989-1994 decline for the nonconvicted than for the convicted, which may relate to the fact that moderate Hutu, including those that protected Tutsi, were also targeted in 1994.

\section{--Figure 6 about here -}

\section{Robustness}

In a series of robustness checks, reported in Supplementary Appendix A5, we show that relying on the unbalanced panel of 471 respondents, using the rankings collected in 2011 for the overlapping 2000-2007 period, and dropping Hutu convicted for property crimes from the category of 'non-convicted' leaves our conclusions intact. 


\section{Alternative Explanations}

So far, we identified ethnic (sub)groups in terms of their roles in the genocidal violence (perpetrator group or victim group) and their individual exposure to it (survivor vs returnee, and convicted vs non-convicted), and we interpreted the changes in trust accordingly. In this section, we acknowledge that the (sub)groups differ in other terms as well. We consider three broad categories of additional differentiations and study their implications on our results : (1) demographic characteristics, (2) post-war processes, and (3) other-than-genocidal violence. Below we discuss our findings. The full results can be consulted in Supplementary Appendix A6.

First, the subgroups differ in terms of demographic characteristics; age and in particular gender. In 2011, our respondents were on average 53 years old, and $37 \%$ were women. While there are no major age differences across subgroups, women are strongly over-represented among Tutsi survivors (61\%) and not at all represented among convicted Hutu (0\%). To verify whether our conclusions remain when controlling for age and gender, we turn to a regression analysis. In particular, we estimate the following equation:

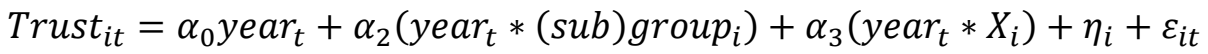

where $i$ indicates an individual respondent, $t$ indicates a year in the period 1989-2011, Trust $_{i t}$ stands for either inter-ethnic or intra-ethnic trust, $\eta_{i}$ are individual fixed effects, and $\varepsilon_{i t}$ is the error term (clustered at the individual level to take into account that observations coming from the same subject are likely to be correlated). We control for the entire set of year dummies, and interact them with an indicator variable for belonging to a particular (sub)group, as well as with the vector $X_{i}$ that includes the respondent's age and an indicator variable taking one for female respondents. The variable (sub)group $i$ corresponds alternatively to the Tutsi ethnic group, the Tutsi survivor subgroup, and the Hutu convicted subgroup. In the latter two cases, we are interested in a within-group comparison and therefore restrict the analytical sample to ethnic Tutsi and Hutu, respectively. The results reveal that our conclusions about the differential trust trajectories across (sub)groups remain qualitatively similar.

Second, the (sub)groups also differ in terms of post-war processes, such as the perceptions of their economic situation and nature of political representation. ${ }^{6}$ Both these

\footnotetext{
${ }^{6}$ In the post-genocide period, approximately $50 \%$ of Rwandan ministers and secretaries of state were Tutsi, and about $75 \%$ of these Tutsi were 'returnees' (Guariso, Ingelaere \& Verpoorten, 2018).
} 
dimensions were systematically ranked by our respondents throughout their life history years. We verify whether controlling for these rankings knocks out our results on differential trust trajectories across the subgroups. To do so, we estimate the following equation:

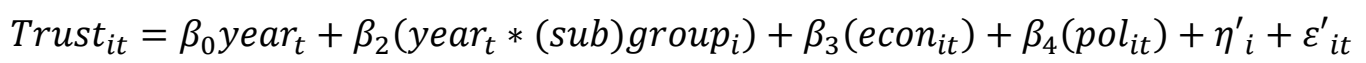

where variables and subscripts are defined as in Equation 1, and $e \operatorname{con}_{i t}$ and pol $_{i t}$ give the rankings of a respondent's perceived economic situation and political representation over time. We find that our results remain similar.

Third, ethnic Hutu were not only the perpetrator group in the genocidal violence, but they were also victims, of other forms of violence including (civil or counterinsurgency) war, reprisal killings, and massacres by the RPF. We cannot systematically control for these forms of violence at the individual level. However, we tentatively explore whether these events confound our results, by exploiting their variation across our seven research localities ${ }^{7}$ (see the overview in Supplementary Appendix A1). To do so, we estimate the following equation:

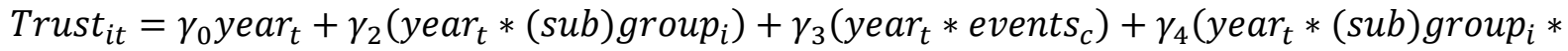
events $\left._{c}\right)+\eta^{\prime \prime}{ }_{i}+\varepsilon^{\prime \prime}{ }_{i t}$

where variables and subscripts are defined as before, and events ${ }_{c}$ is the sum of three separate indicator variables for war, reprisal killings, and massacres, thus taking the values $0,1,2$ or 3 . Our coefficient of interest is $\gamma_{2}$. It captures the differential trust trajectories across (sub)groups in the absence of events in which Hutu were victimized (events $s_{c}=0$ ), and thus more closely aligns with the scope conditions that we specified (Hutu as perpetrator group, and Tutsi as victim group). Again, our results remain similar, except that, when only looking at places where Hutu were not victimized, we find even stronger recovery of inter-ethnic trust among Hutu, and in particular convicted Hutu. This suggest that victimization is a factor that slows down the recovery of inter-ethnic trust, also on the side of Hutu.

\section{Conclusion}

\footnotetext{
${ }^{7}$ For one of the seven localities, 'Butare', information on reprisal killings and massacres by the RPF is missing. In the results presented in Appendix A6, we assigned zero as a default value for these events. Assigning instead one to the events for this location gives qualitatively similar results.
} 
Genocidal violence communicates that no future interactions are foreseen with the outgroup. Consequently, our case study of the 1994 Rwandan genocide against Tutsi was announced as a worst case scenario with respect to the impact of violence on inter-ethnic trust relations. To a large extent, the results for inter-ethnic trust are in line with the hypotheses as derived from theory: inter-ethnic trust declines, most so for those targeted in the genocide and - over time - we find a gradual 'unfreezing' or recovery of inter-ethnic trust.

Interestingly, while we observe a similar initial decline of inter-ethnic trust for the Tutsi subgroups of survivors and returnees, their recovery paths are very different. The recovery is steep and complete for Tutsi returnees, but much slower for Tutsi survivors. This suggests that while the message of group destruction was sufficient for inter-ethnic trust to sharply decline, it is the extent of physical exposure to the annihilation attempt that changes personal predispositions, and installs a persistent mistrust. The relatively slow recovery of inter-ethnic trust among Tutsi survivors requires further study and policy attention. Who exactly remains deeply distrustful and why? Is the mistrust transmitted across generations? These are important questions because outgroup mistrust hampers reconciliation and poses a risk for renewed conflict. The in-depth study of members of the victim group and their descendants can shed further light on this issue. This line of inquiry is slowly gaining traction (Eichelsheim et al., 2019).

On the side of the perpetrator group, we observe different patterns. Those convicted for genocidal violence against humans report significantly lower inter-ethnic trust in 1994, compared to the non-convicted Hutu, but have a steeper recovery path. The direction of causality remains however unclear: is the 1994 low a cause or a consequence of genocidal violence? Further prospective studies of perpetrators and qualitative research could uncover the nature of the underlying processes.

Regarding intra-ethnic trust, we do not find a rise of ingroup trust as predicted by the evolutionary theory of parochial preferences. For Hutu, we find a decline, especially for those not convicted, which is consistent with the fact that moderate Hutu were also targeted by the genocide perpetrators in 1994. For Tutsi, we find a status quo in the early post-violence years, and a gradual erosion of intra-ethnic trust for Tutsi survivors in the peace years after the genocide. This erosion, as well as the other nonlinearities of the post-war trust trajectories, suggests that post-violence processes (transitional justice, post-war aid, economic status, etcetera) may play a role, and change the experience of trustworthiness in social interactions. Further study 
should examine these processes and their impact on trust, for instance through a longitudinal examination of the self-reported reasons of change in (inter- and intra-)ethnic trust levels over time.

More generally, our findings suggest that future studies on the impact of violence on prosocial preferences require more attention to three dimensions. First, since trust revealed to be highly dynamic, the number of peace years needs to be explicitly taken into account. Second, our findings underscore the need to differentiate between in- and outgroup trust, and the relevant inand outgroups to the conflict. Third, more consideration is needed for ethnic subgroups, which may display very different pathways of trust, because they were differently exposed to violence. If not, results might suggest a sort of overall 'phoenix from the ashes'-effect that obscures stark differences within the population.

Replication data: The dataset, codebook, and do-files for the empirical analysis in this article, along with the online appendix, can be found at http://www.prio.org/jpr/datasets. All analyses were conducted using STATA 13. 


\section{References}

African Rights (1998) Rwanda: The Insurgency in the Northwest. African Rights.

Allport, Gordon (1954) The Nature of Prejudice. Cambridge, MA: Perseus Books.

Barber, Brian K, Clea McNeely, Joseph A Olsen, Robert F Belli \& Samuel B Doty (2016) Longterm exposure to political violence: the particular injury of persistent humiliation. Social Science \& Medicine 156 C: 154-166.

Bar-Tal, Daniel \& Eran Halperin (2013) The nature of socio-psychological barriers to peaceful conflict resolution and ways to overcome them. Conflict \& Communication Online 12(2).

Bauer, Michal, Christopher Blattman, Julie Chytilová, Joseph Henrich, Edward Miguel, \& Tamar Mitts (2016) Can war foster cooperation? Journal of Economic Perspectives, 30(3): 24974.

Belli, Robert, William L Shay \& Frank P Stafford (2001) Event history calendars and question list surveys. A direct comparison of interviewing methods. Public Opinion Quarterly 65: 4574.

Bellows, John \& Edward Miguel (2006) War and institutions: New evidence from Sierra Leone. The American Economic Review 96 (2): 394-99.

Blackie, Laura E.R., Nicki Hitchcott \& Stephen Joseph (2017), Looking for post-traumatic growth in perpetrators of the 1994 genocide in Rwanda: A discussion of theoretical and ethical issues, Journal of Perpetrator Research 1 (1), pp. 64-84.

Blattman, Christopher \& Edward Miguel (2010) Civil war. Journal of Economic Literature 48(1): 3-57.

Blouin, Arthur \& Sharun W. Mukand (2019) Erasing ethnicity? Propaganda, nation building, and identity in Rwanda. Journal of Political Economy 127(3): 1008-1062 .

Bowles, Samuel (2006) Group competition, reproductive leveling, and the evolution of human altruism. Science 314: 1569-1572.

Boyd, Robert \& Peter J. Richerson (1985) Culture and the Evolutionary Process. Chicago, IL: University of Chicago Press. 
Brehm, John \& Wendy Rahn (1997) Individual-level evidence for the causes and consequences of social capital. American Journal of Political Science 41: 999-1023.

Brubaker, Rogers (2006) Ethnicity Without Groups. Cambridge: Harvard University Press.

Cassar, Alessandra, Pauline Grosjean \& Sam Whitt (2013) Legacies of violence: trust and market development. Journal of Economic Growth 18(3): 285-318.

Collier, Paul, V. L. Elliott, Håvard Hegre, Anke Hoeffler, Marta Reynal-Querol \& Nicholas Sambanis (2003) Breaking the Conflict Trap: Civil War and Development Policy. World Bank Publications.

Cook, Karen S., Russell Hardin \& Margaret Levi (2005) Cooperation Without Trust? New York: Russell Sage Foundation.

De Luca, Giacomo \& Marijke Verpoorten (2015a) Civil war, social capital and resilience in Uganda. Oxford Economic Papers 67(3): 661-686.

De Luca, Giacomo \& Marijke Verpoorten (2015b) Civil War and political participation: Evidence from Uganda. Economic Development and Cultural Change 64(1): 113-141.

Des Forges, Alison (1999) Leave None to Tell the Story: Genocide in Rwanda. New York: Human Rights Watch.

Ehlers, Anke \& David M Clark (2000) A cognitive model of posttraumatic stress disorder. Behaviour Research and Therapy 38 (4): 319-45.

Eichelsheim, Veroni, Lidewyde H Berckmoes, Barbora Hola, Theoneste Rutayisire \& Annemiek Richters (2019) Before my time?: addressing the intergenerational legacies of the genocide against the Tutsi in Rwanda, Intervention. Journal of Mental Health and Psychosocial Support in Conflict Affected Area, 17 (1): 31-39.

Eisenberg, Nancy \& Paul Henry Mussen (1995) The Roots of Prosocial Behavior in Children. Cambridge: Cambridge University Press.

Freitag, Markus \& Marc Bühlmann (2009) Crafting Trust. The role of political institutions in a comparative perspective. Comparative Political Studies 42(12): 1537 - 1566.

Gilligan, Michael, Benjamin Pasquale \& Cyrus Samii (2013) Civil war and social cohesion: Labin-the-field evidence from Nepal. American Journal of Political Science 58(3): 604-619. 
Gobin, Robyn L \& Jennifer J Freyd (2014). The impact of betrayal trauma on the tendency to trust. Psychological Trauma: Theory, Research, Practice, and Policy 6(5): 505-511

Guariso, Andrea, Ingelaere Bert \& Marijke Verpoorten (2018). Female political representation in the aftermath of ethnic violence: a comparative analysis of Burundi and Rwanda. Development and Change 49(6): 1361-1391.

Hruschka, Daniel \& Joseph Henrich (2013) Economic and evolutionary hypotheses for crosspopulation variation in parochialism. Frontiers in Human Neuroscience 7, 559.

Ingelaere, Bert (2009) Does the truth pass across the fire without burning? Locating the short circuit in Rwanda gacaca courts. The Journal of Modern African Studies 47 (4): 507-528.

Ingelaere, Bert (2010) Peasants, power and ethnicity: a bottom-up perspective on Rwanda's political transition. African Affairs 109 (435): 273-292.

Ingelaere, Bert (2013) Learning 'to be' Kinyarwanda. Reflections on fieldwork, method and data in the study of Rwanda's transition. Working Paper 2013.13. Antwerp: Institute of Development Policy and Management.

Ingelaere, Bert (2016) Inside Rwanda's Gacaca Courts: Seeking Justice After Genocide. Madison: University of Wisconsin Press.

Inglehart, Ronald, Mansoor Moaddel \& Mark Tessler (2006) Xenophobia and ingroup solidarity in Iraq: a natural experiment on the impact of insecurity. Perspectives on Politics 4(3): 495505.

Kalyvas, Stathis N (2006) The Logic of Violence in Civil War. Cambridge: Cambridge University Press.

Kijewski, Sara, Markus Freitag (2018) Civil war and the formation of social trust in Kosovo:

Posttraumatic growth or war-related distress? Journal of Conflict Resolution 62(4): 717-742.

Kunovich, Robert M \& Randy Hodson (1999) Conflict, religious identity, and ethnic intolerance in Croatia. Social Forces 78(2): 643 - 668.

Macnair, Rachel (2002a) The effects of violence on perpetrators, Peace Review 14 (1), 67-72.

Macnair, Rachel (2002b) Perpetrator-induced traumatic stress in combat veterans, Peace and Conflict: Journal of Peace Psychology, 8 (1), 63-72. 
Marotta-Walters, Sylvia, Jaehwa Choi \& Megan D Shaine (2015), Posttraumatic growth among combat veterans: A proposed development pathway, Psychological Trauma: Theory, Research, Practice, and Policy 7 (4): 356-363.

Prunier, Gérard (1995) The Rwanda crisis: History of a genocide. London: Hurst \& Company.

Rohner, Dominic, Mathias Thoenig \& Fabrizio Zilibotti (2013) Seeds of distrust: conflict in Uganda. Journal of Economic Growth 18(3): 217-252.

Scholte, Willem F, Miranda Olff, Peter Ventevogel, Giel-Jan de Vries, Eveline Jansveld, Barbara Lopes Cardozo, \& Carol A Gotway Crawford. (2004) Mental health symptoms following war and repression in eastern Afghanistan. Journal of the American Medical Association 292(5): 585 - 593.

Shewfelt, Steven D (2009) Legacies of War: Social and Political Life after Wartime Trauma. New Haven (CT): Yale University Press.

Steel, Zachary, Derrick Silove, Tuong Phan \& Adrian Bauman. (2002): Long-term effect of psychological trauma on the mental health of Vietnamese refugees resettled in Australia: A population-based study. The Lancet 360(9339): 1056 - 1062.

Straus, Scott (2006) The Order of Genocide. Race, Power and War in Rwanda. Ithaca: Cornell University Press.

Straus, Scott (2015) Making and Unmaking Nations: War, Leadership, and Genocide in Modern Africa. Ithaca and London: Cornell University Press.

Sullivan, John \& John Transue (1999) The psychological underpinnings of democracy: A selective review of research on political tolerance, interpersonal trust, and social capital. Annual Review of Psychology 50: 625-650.

Tedeschi, Richard G \& Lawrence G Calhoun (2004) Posttraumatic growth: conceptual foundations and empirical evidence. Psychological Inquiry 15 (1): 1-18.

Tertsakian, Carina (2008) Le Château. The Lives of Prisoners in Rwanda. London: Arves Books. Traunmüller, Richard, David Born \& Markus Freitag (2015) How civil war experience affects dimensions of social trust in a cross-national comparison. Unpublished manuscript. Available at http://dx.doi.org/10.2139/ssrn.2545816 
UNHCR (2000) Chapter 10: The Rwandan genocide and its aftermath. In: The State of the World's Refugees 2000: Fifty Years of Humanitarian Action.

van der Kolk, Bessel A (1996) The complexity of adaptation to trauma: selfregulation, stimulus discrimination, and characterological development. In Bessel A van der Kolk, Alexander C McFarlane \& Lars Weisaeth (eds) Traumatic Stress: The Effects of Overwhelming Experience on the Mind, Body and Society. New York: Guilford Press, 182-213.

Verpoorten, Marijke (2005) The death toll of the Rwandan genocide: a detailed analysis for Gikongoro Province. Population 60(4): 331-368.

Verpoorten, Marijke (2012a) Leave none to claim the land: A malthusian catastrophe in Rwanda? Journal of Peace Research 49(4): 547-563.

Verpoorten, Marijke (2012b) Detecting hidden violence: The spatial distribution of excess mortality in Rwanda. Political Geography 31(1): 44-56.

Verpoorten, Marijke (2014) Why claim that 200,000 Tutsi died in the genocide is wrong. African Arguments. October 27, 2014. (https://africanarguments.org/2014/10/27/rwanda-whydavenport-and-stams-calculation-that-200000-tutsi-died-in-the-genocide-is-wrong-bymarijke-verpoorten/)

Ward, Michael D, John O'Loughlin, Kristin M Bakke \& Xun Cao (2009) Social distance in BosniaHerzegovina and the North Caucasus region of Russia: Inter and intra-ethnic attitudes and identities. Nations and Nationalism 15(2): 229-255.

Weil, David (2009). Economic Growth. Pearson International Edition.

Wimmer, Adreas (2012) Waves of War: Nationalism, State Formation, and Ethnic Exclusion in the Modern World. Cambridge: Cambridge University Press.

Wohl, Michael J A \& April L McGrath (2007) The perception of time heals all wounds: Temporal distance affects willingness to forgive following an interpersonal transgression. Personality and Social Psychology Bulletin 33 (7): 1023-1035.

Wood, Elisabeth J (2008) The social processes of civil war: The wartime transformation of social networks. Annual Review of Political Science 11: 539-561. 
BERT INGELAERE, b. 1979, PhD in Development Studies (University of Antwerp, 2012); Assistant Professor, University of Antwerp (2016- ).

MARIJKE VERPOORTEN, b. 1977, PhD in Economics (University of Leuven, 2006); Associate Professor, University of Antwerp (2011-). 


\section{Figures \& Tables}

Figure 1. The location of research sites in Rwanda

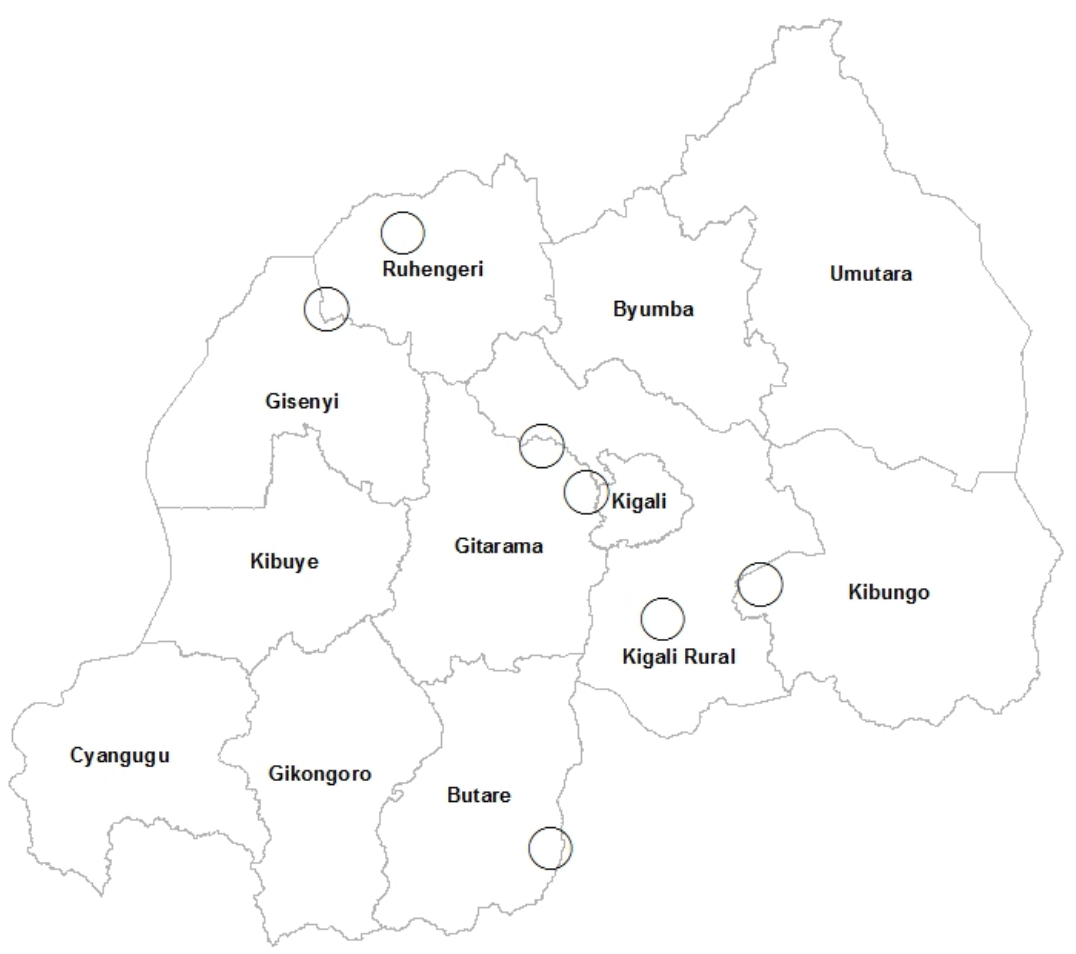

Source: Compiled in ArcGIS. The locations correspond to small administrative sectors. 
Figure 2. Visual aid for ranking exercise

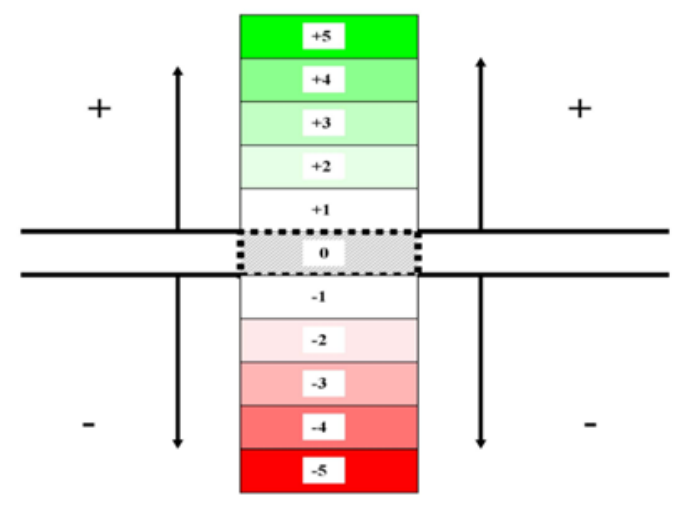


Figure 3. Inter- and intra-ethnic trust, all respondents

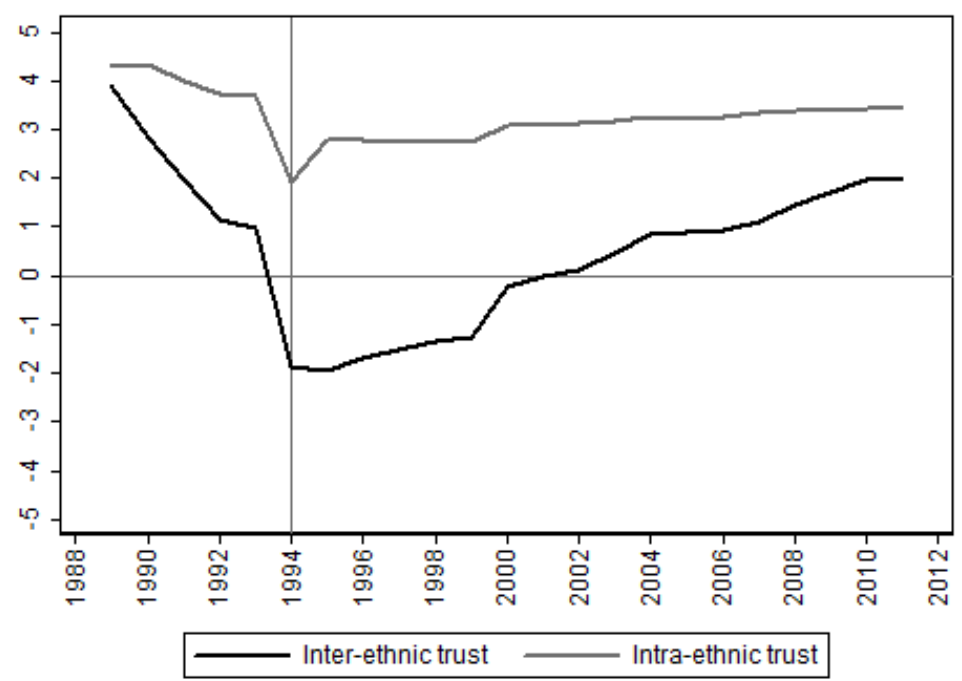

Notes : the data points in the figure rely on the subsample of the 412 respondents that could be traced across the two survey rounds. Round 1 data series are used for the overlapping period 2000-2007. Round 2 data series start from 2007 onwards. The round 2 series are shifted up- or downwards in order for the end point of round 1 to coincide with the starting point of round 2. In a series of robustness checks in Supplementary Appendix A5 we show that neither of these choices affects our qualitative conclusion. 
Figure 4. Inter-ethnic and intra-ethnic trust, Hutu vs. Tutsi

Panel A. Inter-ethnic trust

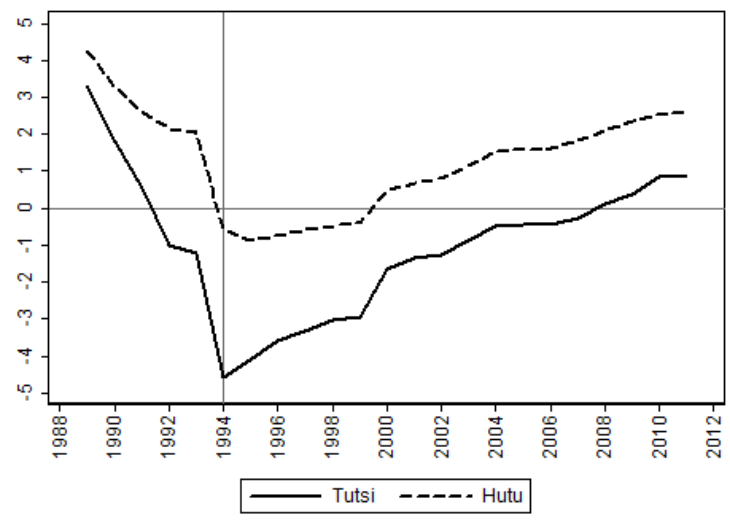

Panel B. Intra-ethnic trust

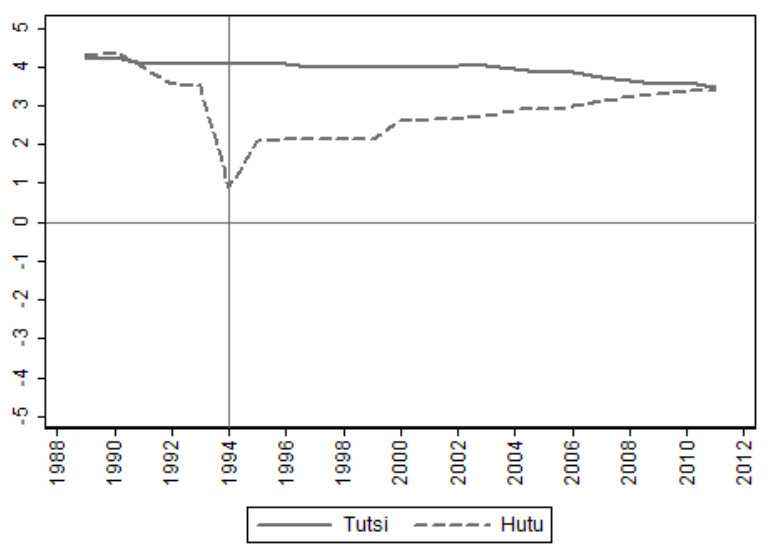

Notes: as in Figure 3. 
Figure 5. Inter-ethnic and intra-ethnic trust, across Tutsi subgroups

Panel A. Inter-ethnic trust

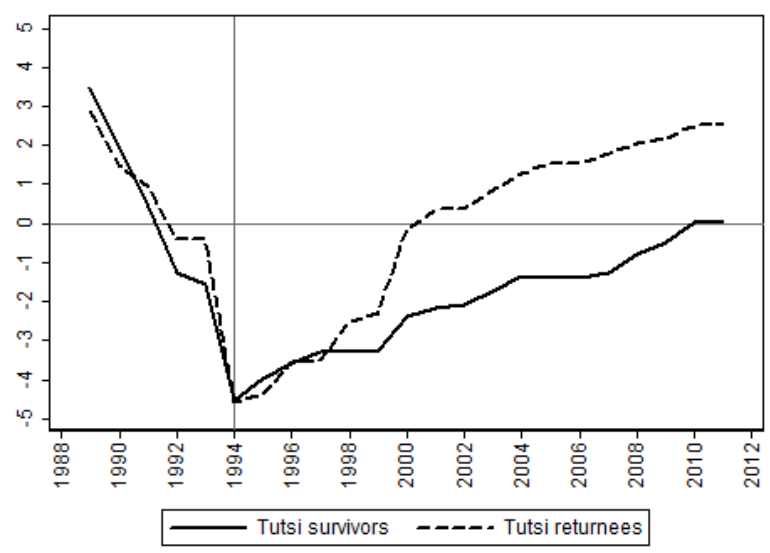

Panel B. Intra-ethnic trust

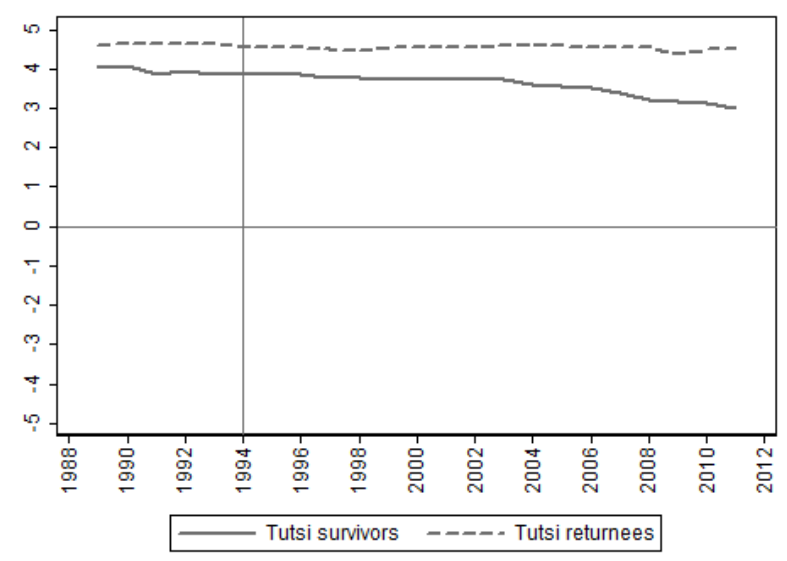

Notes: as in Figure 3. 
Figure 6. Inter-ethnic and intra-ethnic trust, across Hutu subgroups

Panel A. Inter-ethnic trust

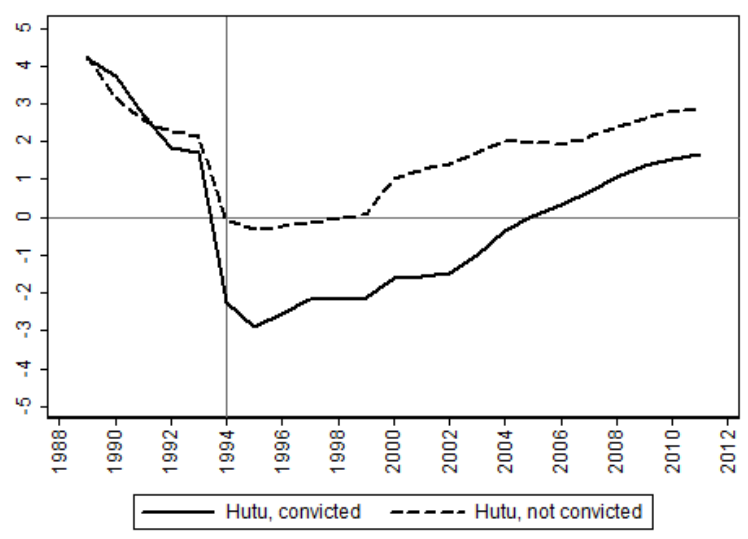

Panel B. Intra-ethnic trust

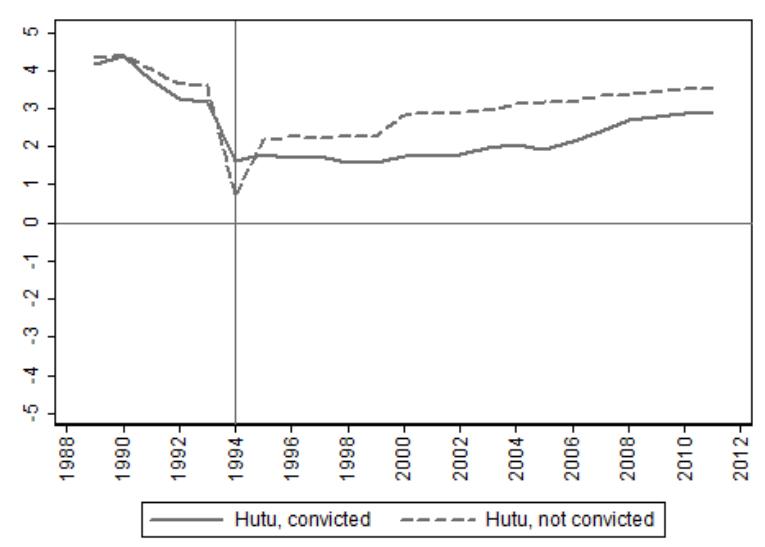

Notes: as in Figure 3. The 'convicted' Hutu include only those convicted for violence against humans. Those convicted for property crimes are included in the category 'not convicted'. 
Table I. Sample observations by ethnic (sub)group, and across interview rounds

\begin{tabular}{cccc}
\hline & $\begin{array}{c}\text { Round 1 } \\
(2007)\end{array}$ & $\begin{array}{c}\text { Round 2 } \\
(2011 \text { and 2015) }\end{array}$ & $\begin{array}{c}\text { Attrition } \\
(\%)\end{array}$ \\
\hline \hline Tutsi & 154 & 138 & $10.4 \%$ \\
Tutsi - survivors & 101 & 93 & $7.9 \%$ \\
Tutsi - returnees & 53 & 45 & $15.1 \%$ \\
\hline Hutu & 317 & 274 & $13.6 \%$ \\
Hutu - not convicted & 245 & 216 & $11.8 \%$ \\
Hutu - convicted & 72 & 58 & $19.4 \%$ \\
\hline All respondents & 471 & 412 & $12.5 \%$ \\
\hline \hline
\end{tabular}

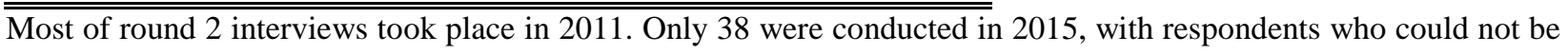
interviewed in 2011. For more information on attrition, see Supplementary Appendix A4. The 'convicted' Hutu include only those convicted for violence against humans. Those convicted for property crimes are included in the category 'not convicted'. 
Table II. Inter- and intra-ethnic trust in 1989, 2000, 2007 and 2011, and its change with respect to 1989

\begin{tabular}{cccccccccc}
\hline & \multicolumn{4}{c}{ Levels } & \multicolumn{4}{c}{ Change with respect to 1989 } \\
& 1989 & 1994 & 2007 & 2011 & 1994 & 2007 & 2011 \\
\hline \hline Inter-ethnic trust & 3.92 & -1.71 & 1.17 & 2.11 & $-5.63^{* *}$ & $-2.75^{* *}$ & $-1.81^{* *}$ \\
Intra-ethnic trust & 4.28 & 1.85 & 3.23 & 3.27 & $-2.43^{* *}$ & $-1.05^{* *}$ & $-1.01^{* *}$ \\
\hline Difference & $-0.36^{* *}$ & $-3.56^{* *}$ & $-2.06^{* *}$ & $-1.16^{* *}$ & $-3.20^{* *}$ & $-1.70^{* *}$ & $-0.80^{* *}$ \\
\hline \hline
\end{tabular}

$\overline{{ }^{\dagger} \mathrm{p}<0.1,{ }^{*} \mathrm{p}<0.05,{ }^{* *} \mathrm{p}<0.01 \text {. The numbers in the table are based on the subsample of } 304 \text { respondents }}$ for which there is a 1989 observation, and which could be traced in round 2. For the overlapping period, 2000-2007, round 1 data are used. A series of robustness checks, shown in Appendix A5, demonstrates that neither of these choices drives our results. 
Table III. Inter-ethnic trust in 1989, 2000, 2007 and 2011, and its change with respect to 1989, across ethnic (sub)groups

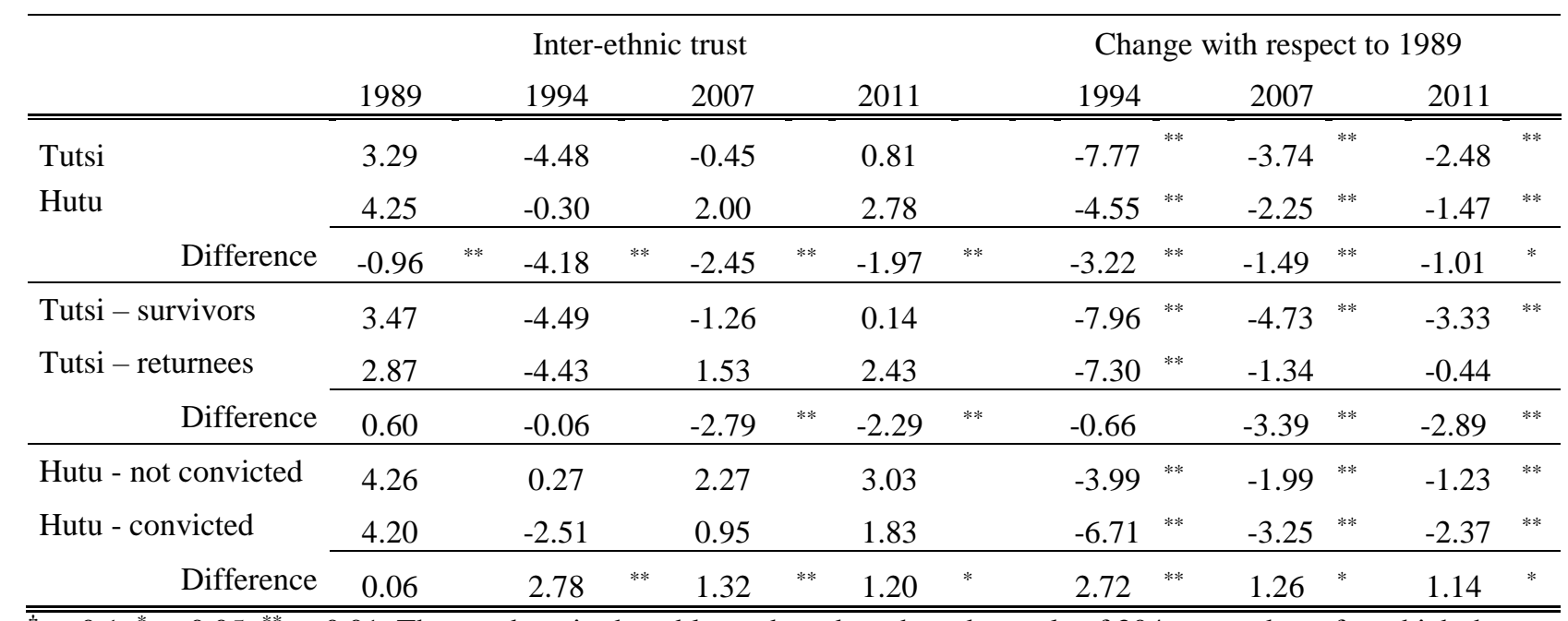

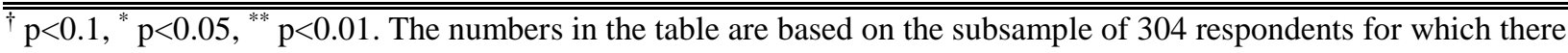
is a 1989 observation, and which could be traced in round 2. For the overlapping period, 2000-2007, round 1 data are used. A series of robustness checks, shown in Appendix A5, demonstrates that neither of these choices drives our results. 
Table IV. Intra-ethnic trust in 1989, 2000, 2007 and 2011, and its change with respect to 1989, across ethnic (sub)groups

\begin{tabular}{|c|c|c|c|c|c|c|c|c|c|c|c|c|c|c|}
\hline & \multicolumn{7}{|c|}{ Intra-ethnic trust } & & \multicolumn{6}{|c|}{ Change with respect to 1989} \\
\hline & \multicolumn{2}{|l|}{1989} & \multicolumn{2}{|c|}{1994} & \multicolumn{2}{|l|}{2007} & \multicolumn{2}{|l|}{2011} & \multicolumn{2}{|c|}{1994} & \multicolumn{2}{|c|}{2007} & \multicolumn{2}{|l|}{2011} \\
\hline Tutsi & 4.21 & & 3.91 & & 3.60 & & 3.24 & & -0.30 & & -0.61 & ** & -0.97 & ** \\
\hline Hutu & 4.31 & & 0.80 & & 3.03 & & 3.28 & & -3.51 & $* *$ & -1.28 & $* *$ & -1.03 & $* *$ \\
\hline Difference & -0.10 & & 3.11 & $* *$ & 0.57 & $*$ & -0.04 & & 3.21 & ${ }^{* *}$ & 0.67 & ** & 0.06 & \\
\hline Tutsi - survivors & 4.05 & & 3.71 & & 3.27 & & 2.79 & & -0.34 & & -0.78 & $*$ & -1.26 & ** \\
\hline Tutsi - returnees & 4.60 & & 4.40 & & 4.40 & & 4.33 & & -0.20 & & -0.20 & & -0.27 & \\
\hline Difference & -0.55 & $\dagger$ & -0.69 & & -1.13 & * & -1.54 & $*$ & -0.14 & & -0.58 & & -0.99 & $\dagger$ \\
\hline Hutu - not convicted & 4.34 & & 0.56 & & 3.21 & & 3.40 & & -3.78 & ** & -1.13 & ** & -0.94 & ** \\
\hline Hutu - convicted & 4.17 & & 1.71 & & 2.34 & & 2.83 & & -2.46 & $* *$ & -1.83 & $* *$ & -1.34 & ** \\
\hline Difference & 0.17 & & -1.15 & $*$ & 0.87 & $* *$ & 0.57 & $\dagger$ & -1.32 & $*$ & 0.70 & $*$ & 0.40 & \\
\hline
\end{tabular}

$\overline{{ }^{\dagger} \mathrm{p}<0.1,{ }^{*} \mathrm{p}<0.05,{ }^{* *} \mathrm{p}<0.01 \text {. The numbers in the table are based on the subsample of } 304 \text { respondents for which }}$ there is a 1989 observation, and which could be traced in round 2. For the overlapping period, 2000-2007, round 1 data are used. A series of robustness checks, shown in Appendix A5, demonstrates that neither of these choices drives our results. 


\title{
Journal of Peace Research
}

First Published April 27, 2020

https://doi.org/10.1177\%2F0022343319899136

\section{Supplementary Appendix}

\author{
Trust in the aftermath of genocide: \\ insights from Rwandan life histories
}

\author{
Bert Ingelaere \\ Assistant Professor. IOB, University of Antwerp \\ bert.ingelaere@uantwerp.be \\ Marijke Verpoorten \\ Associate Professor. IOB, University of Antwerp \\ marijke.verpoorten@uantwerp.be
}




\section{Contents}

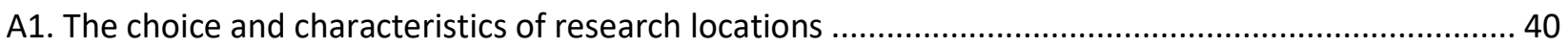

A2. Distribution across ethnic subgroups, by research location ........................................................ 41

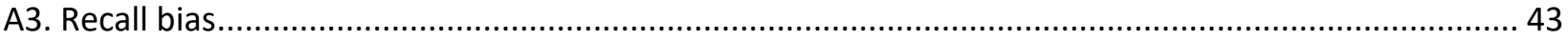

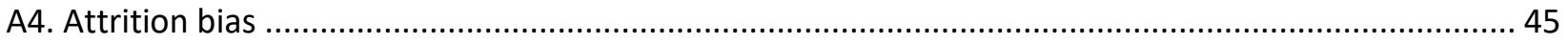

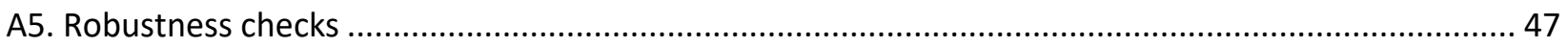

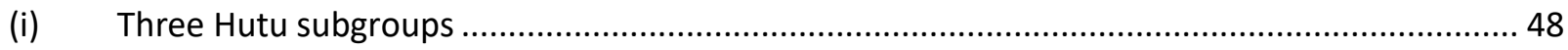

(ii) Round 2 data series for overlapping period ....................................................................... 51

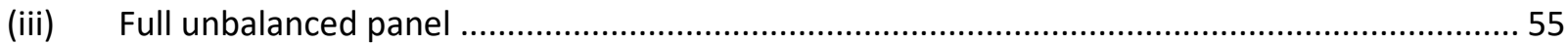

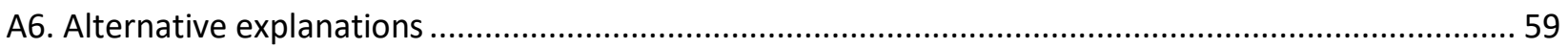

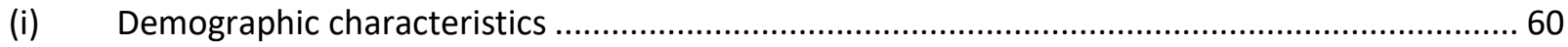

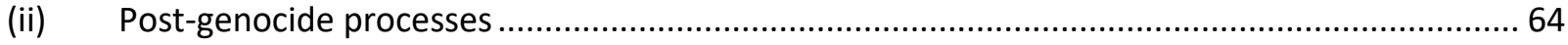

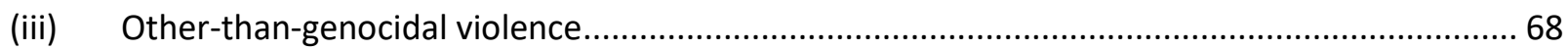




\section{A1. The choice and characteristics of research locations}

The research locations were chosen based on the idea of attaining maximum variance in conflict and post-conflict experiences (see e.g. Varshney, $2002^{8}$ ). Table A1 illustrates the principle of 'maximum variance', showing that research locations vary in terms of the pre-genocide Tutsi population (varying from $0.0 \%$ to $89.2 \%$ ), and the intensity of different forms of violence. Consequently, locations also vary regarding the degree of imprisonment and release of prisoners, and the frequency of accusations and confessions in Gacaca.

The research locations correspond to administrative sectors as they existed during the period of the genocide and until the administrative reform in January 2006. In Table A1, we refer to the corresponding provincial demarcations as they existed at the time of the genocide, and keep sector names confidential (although they may be requested from the authors upon due motivation and confidentiality guarantees).

Table A1. Characteristics of research sites

\begin{tabular}{|c|c|c|c|c|c|c|c|}
\hline Region & South & South & East & East & North & North & South \\
\hline $\begin{array}{l}\text { Province in which research site is } \\
\text { located }\end{array}$ & Gitarama 1 & Gitarama 2 & Rural Kigali & Kibungo & Ruhengeri 1 & Ruhengeri 2 & Butare \\
\hline Hutu Population 1994 & $2885(92.2 \%)$ & $4303(81.7 \%)$ & $6190(74.7 \%)$ & $1618(10.8 \%)$ & $7325(93.7 \%)$ & $1368(99.9 \%)$ & $5220(75.8 \%)$ \\
\hline Tutsi Population 1994 & $245(7.8 \%)$ & $1088(18.3 \%)$ & $2096(25.3 \%)$ & $13366(89.2 \%)$ & $499(6.3 \%)$ & $2(0.0 \%)$ & $1667(24.2 \%)$ \\
\hline Tutsi Inhabitants Killed & $158(64 \%)$ & $553(51 \%)$ & $1775(85 \%)$ & $12828(96 \%)$ & $416(83 \%)$ & $0(0.0 \%)$ & $817(49 \%)$ \\
\hline Civil War (1990-1994) & Low & Low & No & No & Medium & High & No \\
\hline Insurgency War (1996-1999) & Low & Low & No & No & High & High & No \\
\hline Massacres (RPF) & No & No & No & Yes & Yes & Yes & n.a. \\
\hline Revenge Killings & No & Yes & Yes & Yes & Yes & No & n.a. \\
\hline Hutu Population in pris on $\left(\%^{\prime} 94\right)$ & $58(2 \%)$ & $215(5 \%)$ & $557(9 \%)$ & $239(14,8 \%)$ & N/A & $0.00 \%$ & n.a. \\
\hline Prisoners released & 9 & 149 & 374 & 41 & 0 & 1 & n.a. \\
\hline Hutu Population Accused (\% '94) & $833(28.8 \%)$ & $1950(45.3 \%)$ & $1526(24.6 \%)$ & $1037(64 \%)$ & $693(9 \%)$ & $35(2.5 \%)$ & $1319(25.3 \%)$ \\
\hline Confessions by ' 06 (\% of accused) & $42(5 \%)$ & $123(6 \%)$ & $565(37 \%)$ & $3(0.2 \%)$ & $43(6.2 \%)$ & $0(0 \%)$ & n.a. \\
\hline
\end{tabular}

The characteristics of the research sites were collected during fieldwork in 2006/7, mostly by relying on key informants, except for the population statistics of the sector located in Butare province, which were derived from the 1991 population census (as calculated in Verpoorten, $2012^{9}$ ). In addition, the 'Hutu Population Accused' was calculated from a summary report provided by the National Service of the Gacaca Courts (SNJG) on Gacaca proceedings detailing number of people accused at sector level in 2006 (on file with the authors).

\footnotetext{
${ }^{8}$ Varshney, Ashutosh (2002) Ethnic conflict and civic life. Hindus and Muslims in India. New Haven: Yale University Press.

${ }^{9}$ Verpoorten, Marijke (2012) Leave None to Claim the Land: A Malthusian Catastrophe in Rwanda? Journal of Peace Research 49(4): 547-563.
} 


\section{A2. Distribution across ethnic subgroups, by research location}

To select individuals, lists were compiled with the names of all household heads in each location. Subsequently households were selected through a random sampling scheme, by the prevalent ethnic subgroups in the location. For Tutsi, these subgroups were 'survivors' and 'returnees'. For Hutu, at that time of the sampling, these were 'not accused/imprisoned', 'accused in gacaca', and 'released prisoner'. We oversampled some population groups (Tutsi and liberated prisoners), since we wanted to include a fair number of each of the five subgroups. In some locations, however, very few Tutsi could be found, and others did not harbor released prisoners. This results from our choice of 'maximum variance' across our locations.

Table A2 gives the complete overview of the observations per subgroup, across research sites, for the subsample of 412 traced observations. In one of our northern research locations ('Ruhengeri 2'), only two Tutsi were living at the time of the genocide. Both of them survived, and were included in our sample. In three out of the seven sites, no Tutsi returnees settled, and are therefore also absent from our sample in those locations. One location did not harbor released prisoners.

Table A2. Distribution across ethnic subgroups, by research location

\begin{tabular}{|c|c|c|c|c|c|c|c|}
\hline $\begin{array}{l}\text { Province in which research site } \\
\text { is located }\end{array}$ & Gitarama 1 & Gitarama 2 & Kigali Rural & Kibungo & Ruhengeri 1 & Ruhengeri 2 & Butare \\
\hline Tutsi- survivor & 14 & 21 & 15 & 15 & 12 & 2 & 14 \\
\hline Tutsi - returnee & 0 & 6 & 13 & 14 & 12 & 0 & 0 \\
\hline Hutu - not accused /no prison & 19 & 17 & 15 & 18 & 8 & 40 & 14 \\
\hline Hutu - accused in gacaca & 15 & 11 & 12 & 10 & 15 & 0 & 15 \\
\hline Hutu - released prisoner & 9 & 12 & 15 & 14 & 0 & 1 & 14 \\
\hline Total & 57 & 67 & 70 & 71 & 47 & 43 & 57 \\
\hline
\end{tabular}

When the gacaca process ended, we could re-classify Hutu into the two subcategories that we use in the main analysis of the paper: 'not convicted' and 'convicted'. This status could be derived from the records of the gacaca process that was systemically observed in six of the seven 
research locations. ${ }^{10}$ The first author of this paper, together with Rwandan collaborators, observed a total of 1917 trials dealing with allegations against 2573 individuals. ${ }^{11}$ The gacaca process differentiated crimes against humans from acts of pillaging and destruction of property. In our analysis, 'convicted' is short for 'convicted for crimes against humans', which means the individual is part of one of the following categories: (1) well known murderers; (2) torturers; (3) persons who committed dehumanizing acts on a dead body; (4) 'ordinary killers'; (5) those who committed attacks in order to kill but without attaining this goal; (6) those who committed attacks against others, without the intention to kill. Thus, in our sample, the 'convicted' exclude those individuals only convicted for 'committing property offences'.

The information derived from these observations was corroborated with the information available in the life histories conducted in 2011/15. The gacaca process was not systematically observed in one research location (Butare). The information on (the nature of) conviction in this location was systematically recorded during the life history interviews conducted in 2011/15. Table A2' gives the distribution of these groups across research locations.

Table A2'. Distribution across convicted and non-convicted Hutu, by research location

\begin{tabular}{lccccccc}
\hline $\begin{array}{l}\text { Province in which research site } \\
\text { is located }\end{array}$ & Gitarama 1 & Gitarama 2 & Kigali Rural & Kibungo & Ruhengeri 1 & Ruhengeri 2 & Butare \\
\hline Hutu - not convicted & 32 & 27 & 27 & 33 & 23 & 41 & 33 \\
Hutu - convicted & 11 & 13 & 15 & 9 & 0 & 0 & 10 \\
\hline Total hutu & 43 & 40 & 42 & 42 & 23 & 41 & 43 \\
\hline
\end{tabular}

The 'convicted' Hutu include only those convicted for violence against humans. Those convicted for property crimes are included in the category 'not convicted'. Supplementary Appendix A5i looks at these two categories of convicted separately.

\footnotetext{
${ }^{10}$ The gacaca courts dealt with the legacy of the 1994 genocide against Tutsi. They were characterized by a decentralization of the judicial procedure to the lowest levels of society, a popularization or diffusion of the process among lay judges, and the involvement of the general population. Between the nationwide introduction in 2005 and official closure of the modern gacaca system in June 2012, over 11,000 courts dealt with 1,958,634 cases of alleged participation in the genocide.

${ }^{11}$ The research methodology, the nature of the fieldwork activities and the working of the gacaca courts is extensively discussed in Ingelaere $(2013,2015$ \& 2016).
} 


\section{A3. Recall bias}

Self-reported information suffers from memory failure, and may be colored through the lens of more recent events. Imagine for instance a respondent being interviewed not long after being accused in a Gacaca trial. Because of this recent negative experience, s/he may report fairly low inter-ethnic trust levels, not only for the present, but also for years that precede the accusations. In this case, pre-Gacaca recall data on self-reported inter-ethnic trust will be biased downward for those accused in Gacaca. More generally, if recall bias is systematically positive, negative, or relates to characteristics of our respondents (e.g. ethnic (sub)group), it will affect our results.

In the main text, we argued that recall bias is likely to be low, as suggested by the relatively small (but significant) average difference of inter-ethnic trust $\left(-0.23^{* *}\right)$ and intra-ethnic trust ($0.40^{* *}$ ) across rounds 1 and 2, for the overlapping period 2000-2007. The average gap hides however heterogeneity across ethnic subgroups. Table A3 gives an overview of recall bias by ethnic subgroup. It shows that, for the overlapping period 2000-2007, round 2 inter-ethnic trust is lower than round 1 inter-ethnic trust for Tutsi returnees $\left(-0.45^{*}\right)$, and for Hutu that were convicted $\left(-0.44^{*}\right)$. The latter may indicate that recollection of the past is affected by the negative experience of being convicted. In contrast, looking back in 2011 rather than in 2007, yields higher recollected inter-ethnic trust levels for Tutsi survivors $\left(0.28^{\dagger}\right)$. At the risk of being speculative, we could argue that the recollection of Tutsi survivors is affected by the unfolding of Gacaca during which they discovered that not all Hutu participated in or even supported the extermination campaign. This data exploration underlines that the recollection process is interesting in itself: since respondents perceive and re-interpret the past through the lens of more recent events, life history data can be considered as a (social) commentary, and can be analyzed as such. Analyzing this recollection process is outside the scope of this paper. What is important for the present analysis, is that - when using the 2011 instead of the 2007 data series for the overlapping recollection period (2000-2007), our results remain qualitatively the same (see Appendix A5). 
Table A3. Recall bias by ethnic subgroup

\begin{tabular}{lcccccc}
\hline & \multicolumn{3}{c}{ Inter-ethnic trust, 2000-2007 } & \multicolumn{2}{c}{ Intra-ethnic trust, 2000-2007 } \\
& $\begin{array}{l}\text { Round 1 } \\
(\mathrm{N}=412)\end{array}$ & $\begin{array}{l}\text { Round 2 } \\
(\mathrm{N}=412)\end{array}$ & $\begin{array}{c}\text { Diff. } \begin{array}{l}\text { T- } \\
\text { test })\end{array} \\
\text { Round 1 } \\
(\mathrm{N}=412)\end{array}$ & $\begin{array}{c}\text { Round 2 } \\
(\mathrm{N}=412)\end{array}$ & $\begin{array}{c}\text { Diff. T- } \\
\text { test })\end{array}$ \\
\hline Tutsi - survivor & -1.72 & -1.44 & $0.28 \dagger$ & 3.63 & 3.38 & $-0.25 *$ \\
Tutsi - returnee & 0.95 & 0.50 & $-0.45 *$ & 4.57 & 3.50 & $-1.07 * *$ \\
Hutu - not convicted & 1.69 & 1.35 & $-0.34 * *$ & 3.05 & 2.85 & $-0.20 * *$ \\
Hutu - convicted & -0.61 & -1.08 & $-0.44 *$ & 1.98 & 1.07 & $-0.88 * *$ \\
\hline Total sample & 0.51 & 0.28 & $-0.23 * *$ & 3.20 & 2.79 & $-0.40 * *$ \\
\hline
\end{tabular}

${ }^{\dagger} \mathrm{p}<0.1,{ }^{*} \mathrm{p}<0.05,{ }^{* *} \mathrm{p}<0.01$. The 'convicted' Hutu include only those convicted for violence against humans. Those convicted for property crimes are included in the category 'not convicted'. 


\section{A4. Attrition bias}

The first wave of life history interviews was conducted between January and April 2007. Due to practical circumstances, the life history interviewing in one location took place in December 2007January 2008. The findings from this location are currently integrated in the study but they were not part of previous publications that made use of the life history data (Ingelaere 2009, 2010). ${ }^{12} \mathrm{~A}$ second wave was organized between January and June 2011. The 2011 life story survey focused on the period 2000-2011 in order to complete and complement the 2007 survey results.

In between the 2007 and 2011 rounds, attrition was 18.9\%, which is unusually large. The enumerators systematically recorded the reasons why people were not available. These reasons were diverse: among the 89 drop-outs, 15 had died, 14 were imprisoned, 13 were executing community service, 36 had migrated or were on the run and 11 were temporarily unavailable due to visits or work-related reasons. Many of those imprisoned or in camps conducting community service had been released by 2015 and therefore we decided to try and trace them. In total, 30 additional respondents could be traced. Attrition thus reduced considerably, from $18.9 \%$ to $12.5 \%$. Attrition remained however non-random, e.g. the share of non-traced respondents is still higher among those convicted (19.4\%) than among Tutsi survivors (7.9\%).

If the probability to drop out relates to a respondent's levels and changes in trust, then our results will be biased. For instance, suppose that the least trusting individuals drop out (e.g. because they migrate, are imprisoned, or sent to re-education camps) then we may overestimate the recovery of trust, i.e. we will conclude there is a large recovery of trust between rounds 1 and 2 whereas part of the recovery stems from the least trusting individuals dropping out. Exploring attrition bias across ethnic subgroups in Table A4, we find that the difference in inter-ethnic trust between the drop-outs and traced observations is especially high for Tutsi returnees: for those that dropped out, the 1989-2007 average of the reported inter-ethnic trust levels was as high as 1.23, compared to 0.54 for those that remained in the sample. Also for Tutsi survivors and convicted Hutu, it are those with the highest reported inter-ethnic trust in the period 1989-2007 that were more likely to drop out. We are thus at a risk of underestimating the recovery of trust. In a robustness check, presented

\footnotetext{
${ }^{12}$ Ingelaere, Bert (2009) Living the transition. Inside Rwanda's conflict cycle at the grassroots. Journal of eastern African studies 3 (3): 438-463.

Ingelaere, Bert (2010) Peasants, power and ethnicity. A bottom-up perspective on Rwanda's political transition. African affairs 108 (433): 273-292.
} 
in Appendix A5 we show that - despite these significant differences - our qualitative conclusions are robust to using the unbalanced panel of 471 respondents.

Table A4. Attrition bias by ethnic subgroup

\begin{tabular}{|c|c|c|c|c|c|c|c|}
\hline & \multicolumn{3}{|c|}{ Inter-ethnic trust, 1989-2007 } & \multicolumn{3}{|c|}{ Intra-ethnic trust, 1989-2007 } & \multirow{2}{*}{$\begin{array}{l}\text { Attrition } \\
(\%)\end{array}$} \\
\hline & $\begin{array}{c}\text { Traced } \\
\text { observation } \\
(\mathrm{N}=412)\end{array}$ & $\begin{array}{l}\text { Drop-outs } \\
(\mathrm{N}=59)\end{array}$ & $\begin{array}{l}\text { (Sig. } \\
\text { Diff. T- } \\
\text { test) }\end{array}$ & $\begin{array}{c}\text { Traced } \\
\text { observation } \\
(\mathrm{N}=412)\end{array}$ & $\begin{array}{l}\text { Drop-outs } \\
(\mathrm{N}=59)\end{array}$ & $\begin{array}{l}\text { (Sig. } \\
\text { Diff. T- } \\
\text { test) }\end{array}$ & \\
\hline Tutsi - survivor & -1.78 & -0.92 & $0.86 * *$ & 3.77 & 4.24 & $0.47 *$ & $7.9 \%$ \\
\hline Tutsi - returnee & -0.54 & 1.23 & $1.77 * *$ & 4.57 & 4.53 & -0.03 & $15.1 \%$ \\
\hline Hutu - not convicted & 1.39 & 1.21 & -0.18 & 2.94 & 3.51 & $0.57 * *$ & $11.8 \%$ \\
\hline Hutu - convicted & -0.31 & 0.48 & $0.79 * *$ & 2.32 & 2.85 & $0.53 * *$ & $19.4 \%$ \\
\hline Total sample & 0.23 & 0.74 & $0.51 * *$ & 3.21 & 3.57 & $0.36 * *$ & $12.5 \%$ \\
\hline
\end{tabular}

${ }^{\dagger} \mathrm{p}<0.1,{ }^{*} \mathrm{p}<0.05,{ }^{* *} \mathrm{p}<0.01$. The 'convicted' Hutu include only those convicted for violence against humans. Those convicted for property crimes are included in the category 'not convicted'. 


\section{A5. Robustness checks}

In our baseline analysis, we made three choices in the treatment of our data. First, we relied on the life histories of the 412 respondents that could be traced over time. Second, for the overlapping period 2000-2007, we analyzed the rankings as reported in the first data round, in 2007. Third, when distinguishing between convicted and non-convicted Hutu, we restricted the 'convicted' to those convicted for violence against humans, and classified those only convicted for property crimes with the 'non-convicted'. In a series of robustness checks, we replicate the main tables and figures of our baseline analysis, while making different choices regarding the categorization of Hutu subgroups, the time series used for the overlapping period, and the analytical sample. 


\section{(i) Three Hutu subgroups}

In our baseline results, we distinguish between two Hutu subgroups: the 'convicted' and the 'non-convicted'. The convicted include those individuals that were convicted for crimes against humans (cf. Supplementary appendix A2). Those convicted only for property crimes are pooled with the non-convicted. In what follows, we repeat our analysis while distinguishing between the three Hutu subgroups: 'not convicted', 'convicted for pillaging' and 'convicted for violence'. It is noteworthy that the trust trajectories of Hutu convicted for property crimes show much more resemblance with those of the non-convicted Hutu than with those of Hutu convicted for violence against humans. This supports our initial categorization.

\section{Replication of Figure 6. Inter-ethnic and Intra-ethnic trust, across Hutu subgroups}

Panel A. Inter-ethnic trust

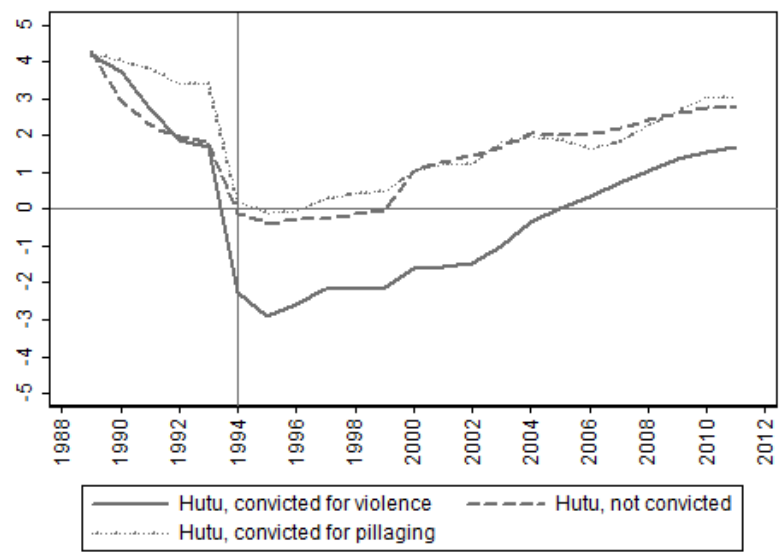

Panel B. Intra-ethnic trust

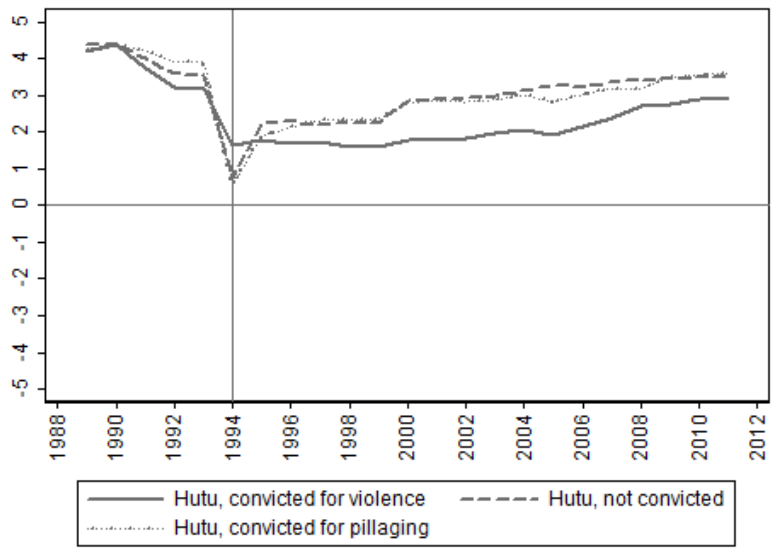

The data points in the figure rely on the subsample of the 412 respondents that could be traced across the two survey rounds. Round 1 data series are used for the overlapping period 2000-2007. Round 2 data series start from 2007 onwards. The round 2 series are shifted up- or downwards in order for the end point of round 1 to coincide with the starting point of round 2. 
Table 1. Sample observations by ethnic (sub)group, and across interview rounds

\begin{tabular}{lccc}
\hline & $\begin{array}{c}\text { Round 1 } \\
(2007)\end{array}$ & $\begin{array}{c}\text { Round 2 } \\
(2011 \text { and 2015) }\end{array}$ & $\begin{array}{c}\text { Attrition } \\
(\%)\end{array}$ \\
\hline \hline Tutsi & 154 & 138 & $10.4 \%$ \\
Tutsi - survivors & 101 & 93 & $7.9 \%$ \\
Tutsi - returnees & 53 & 45 & $15.1 \%$ \\
\hline Hutu & 317 & 274 & $13.6 \%$ \\
Hutu - not convicted & 189 & 172 & $9.0 \%$ \\
Hutu - convicted for pillaging & 56 & 44 & $21.4 \%$ \\
Hutu - convicted for violence & 72 & 58 & $19.4 \%$ \\
\hline All respondents & 471 & 412 & $12.5 \%$ \\
\hline
\end{tabular}

Most of round 2 interviews took place in 2011. Only 38 were conducted in 2015, with respondents who could not be interviewed in 2011. For more information on attrition, see Supplementary Appendix A4.

Replication of Table 3. Inter-ethnic trust in 1989, 2000, 2007 and 2011, and its change with respect to 1989, across ethnic (sub)groups

\begin{tabular}{|c|c|c|c|c|c|c|c|c|c|c|c|c|}
\hline & \multicolumn{8}{|c|}{ Inter-ethnic trust } & \multicolumn{4}{|c|}{ Change with respect to 1989} \\
\hline & \multicolumn{2}{|l|}{1989} & \multicolumn{2}{|c|}{1994} & \multicolumn{2}{|l|}{2007} & \multicolumn{2}{|l|}{2011} & 1994 & 2007 & \multicolumn{2}{|l|}{2011} \\
\hline Tutsi & 3.29 & & -4.48 & & -0.45 & & 0.81 & & $-7.77^{* *}$ & $-3.74^{* *}$ & -2.48 & *** \\
\hline \multirow[t]{2}{*}{ Hutu } & 4.25 & & -0.30 & & 2.00 & & 2.78 & & $-4.55^{* *}$ & $-2.25^{* *}$ & -1.47 & $* *$ \\
\hline & -0.96 & ** & -4.18 & *** & -2.45 & *** & -1.97 & *** & $-3.22^{* * *}$ & $-1.49^{* *}$ & -1.01 & * \\
\hline Tutsi - survivors & 3.47 & & -4.49 & & -1.26 & & 0.14 & & $-7.96^{* *}$ & $-4.73^{* *}$ & -3.33 & ** \\
\hline \multirow[t]{2}{*}{ Tutsi - returnees } & 2.87 & & -4.43 & & 1.53 & & 2.43 & & $-7.30^{* *}$ & -1.34 & -0.44 & \\
\hline & 0.60 & & -0.06 & & -2.79 & ** & -2.29 & ** & -0.66 & $-3.39^{* *}$ & -2.89 & ** \\
\hline Hutu - not convicted & 4.23 & & 0.38 & & 2.37 & & 2.92 & & $-3.85^{* *}$ & $-1.86^{* *}$ & -1.31 & ** \\
\hline Hutu - convicted & 4.37 & & -0.14 & & 1.91 & & 3.40 & & $-4.51^{* *}$ & $-2.46^{* *}$ & -0.97 & * \\
\hline Hutu - convicted for violence & 4.19 & & -2.51 & & 0.95 & & 1.83 & & $-6.70^{* *}$ & $-3.24^{* *}$ & $-2.36^{*}$ & \\
\hline $\begin{array}{r}\text { Difference between 'not convicted' and } \\
\text { 'convicted for violence' }\end{array}$ & 0.04 & & 2.89 & ** & 1.42 & ** & 1.09 & * & $2.85^{* *}$ & $1.38^{* *}$ & 1.05 & * \\
\hline
\end{tabular}

${ }^{\dagger} \mathrm{p}<0.1,{ }^{*} \mathrm{p}<0.05,{ }^{* *} \mathrm{p}<0.01$. The numbers in the table are based on the subsample of 304 respondents for which there is a 1989 observation, and which could be traced in round 2. For the overlapping period, 2000-2007, round 1 data are used. 
Replication of Table 4. Intra-ethnic trust in 1989, 2000, 2007 and 2011, and its change with respect to 1989, across ethnic (sub)groups

\begin{tabular}{|c|c|c|c|c|c|c|c|c|c|c|c|c|c|c|}
\hline & \multicolumn{7}{|c|}{ Intra-ethnic trust } & & \multicolumn{6}{|c|}{ Change with respect to 1989} \\
\hline & 1989 & & 1994 & & 2007 & & 2011 & & 1994 & & 2007 & & 2011 & \\
\hline Tutsi & 4.21 & & 3.91 & & 3.60 & & 3.24 & & -0.30 & & -0.61 & ${ }^{* *}$ & -0.97 & ${ }^{* *}$ \\
\hline \multirow[t]{2}{*}{ Hutu } & 4.31 & & 0.80 & & 3.03 & & 3.28 & & -3.51 & $* *$ & -1.28 & ** & -1.03 & ** \\
\hline & -0.10 & & 3.11 & ** & 0.57 & * & -0.04 & & 3.21 & ** & 0.67 & ** & 0.06 & \\
\hline Tutsi - survivors & 4.05 & & 3.71 & & 3.27 & & 2.79 & & -0.34 & & -0.78 & * & -1.26 & ** \\
\hline \multirow[t]{2}{*}{ Tutsi - returnees } & 4.60 & & 4.40 & & 4.40 & & 4.33 & & -0.20 & & -0.20 & & -0.27 & \\
\hline & -0.55 & + & -0.69 & & -1.13 & * & -1.54 & $*$ & -0.14 & & -0.58 & & -0.99 & + \\
\hline Hutu - not convicted & 4.34 & & 0.50 & & 3.24 & & 3.34 & & -3.84 & ** & -1.10 & ** & -1.00 & ** \\
\hline Hutu - convicted for pillaging & 4.37 & & 0.77 & & 3.11 & & 3.60 & & -3.60 & ** & -1.26 & ** & -0.77 & * \\
\hline Hutu - convicted for violence & 4.17 & & 1.70 & & 2.34 & & 2.83 & & -2.47 & ** & -1.83 & ** & -1.34 & ** \\
\hline $\begin{array}{r}\text { Difference between 'not convicted' and } \\
\text { 'convicted for violence' }\end{array}$ & 0.17 & & -1.20 & ${ }^{*}$ & 0.90 & $*$ & 0.51 & + & -1.37 & $*$ & 0.73 & $*$ & 0.34 & \\
\hline
\end{tabular}

\footnotetext{
${ }^{\dagger} \mathrm{p}<0.1,{ }^{*} \mathrm{p}<0.05,{ }^{* *} \mathrm{p}<0.01$. The numbers in the table are based on the subsample of 304 respondents for which there is a 1989 observation, and which could be traced in round 2. For the overlapping period, 2000-2007, round 1 data are used.
} 
Round 1 took place in 2007; round 2 in 2011. In round 2, respondents started telling their life history from the year 2000 onwards. As a result, for the period 2000-2007, we have overlapping time series from round 1 and round 2 . In our baseline results, we only used round 1 data for the overlapping period. And, to connect the two series seamlessly, we shifted the 2011 series with a distance equal to the difference between the 2007 ranking in round 1 and the 2007 ranking in round 2. For instance, if in the respondent gave a ranking of 2 in round 1 for her 2007 inter-ethnic trust and a ranking of 3 in round 2 for her 2007 inter-ethnic trust, we shifted the entire time series for the period 2007-2011 down with 1 unit.

In the following figures and tables, we fully display both the round 1 and round 2 series. An inspection of the figures and tables reveals that our conclusions remain when we would make other choices to merge the round 1 and round 2 data series. A finding that would be more pronounced is the relatively rapid recovery of inter-ethnic trust of Hutu convicted compared to Hutu non-convicted. Another difference relates to the post-genocide trajectory of intra-ethnic trust for Tutsi returnees, which is lower, and similar to that of Tutsi survivors, when relying on round 2 time series data.

\section{Replication of 'Figure 3. Inter- and Intra-ethnic trust, all respondents' with round 1 and round 2 rankings fully displayed}

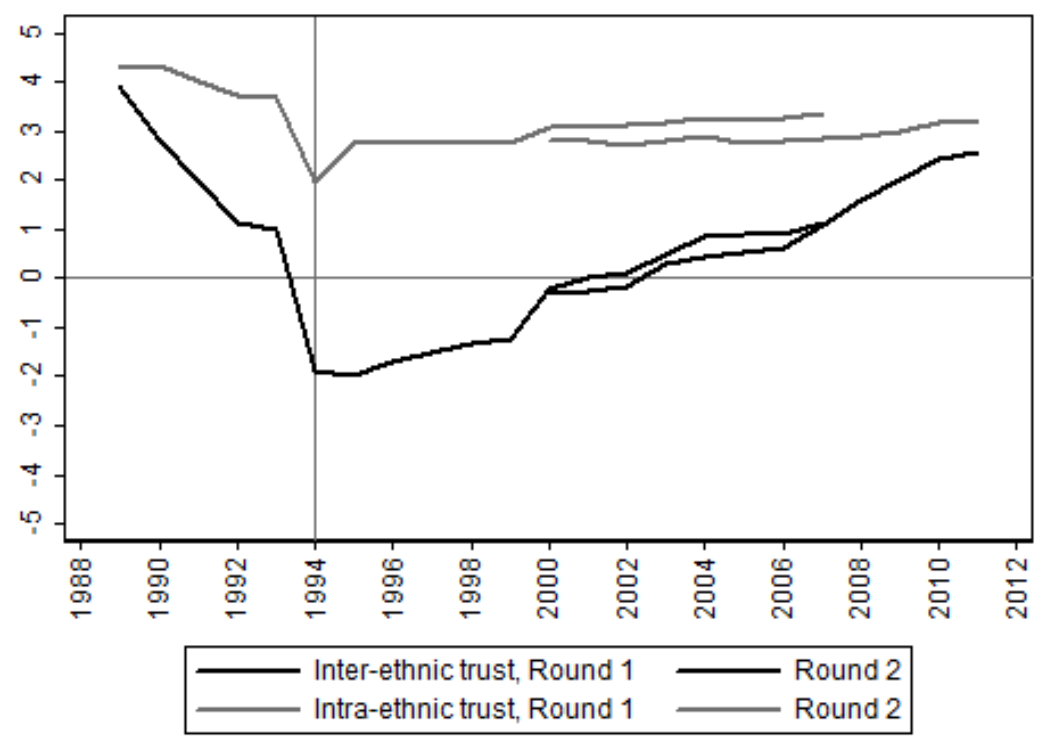

The data points in the figure rely on the subsample of the 412 respondents that could be traced across the two survey rounds.

Round 1 and round 2 data series are fully displayed, also for the overlapping period 2000-2007. 


\section{Replication of 'Figure 4. Inter-ethnic and Intra-ethnic trust, Hutu vs. Tutsi' with full display of round 1 and round 2 data series}

Panel A. Inter-ethnic trust

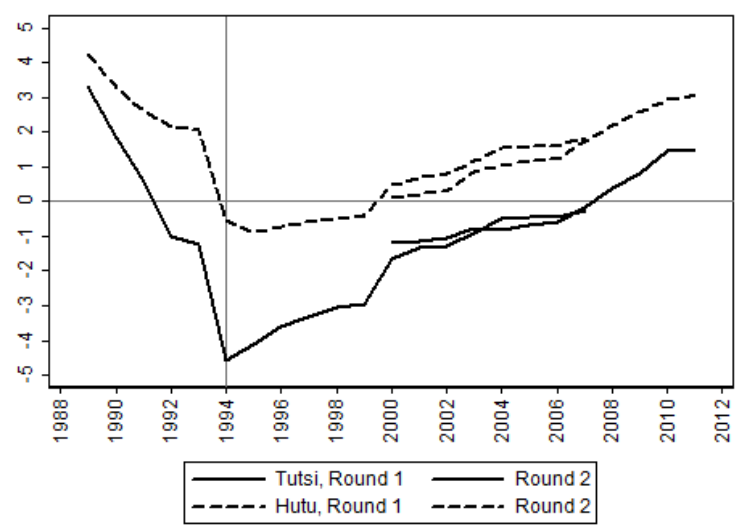

Panel B. Intra-ethnic trust

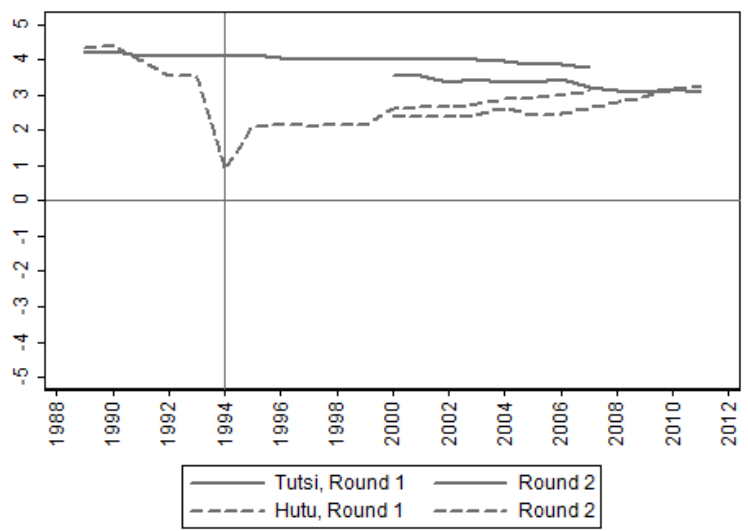

The data points in the figure rely on the subsample of the 412 respondents that could be traced across the two survey rounds.

Round 1 and round 2 data series are fully displayed, also for the overlapping period 2000-2007.

\section{Replication of 'Figure 5. Inter-ethnic and Intra-ethnic trust, across Tutsi subgroups' with full display of round 1 and round 2 data series}

Panel A. Inter-ethnic trust

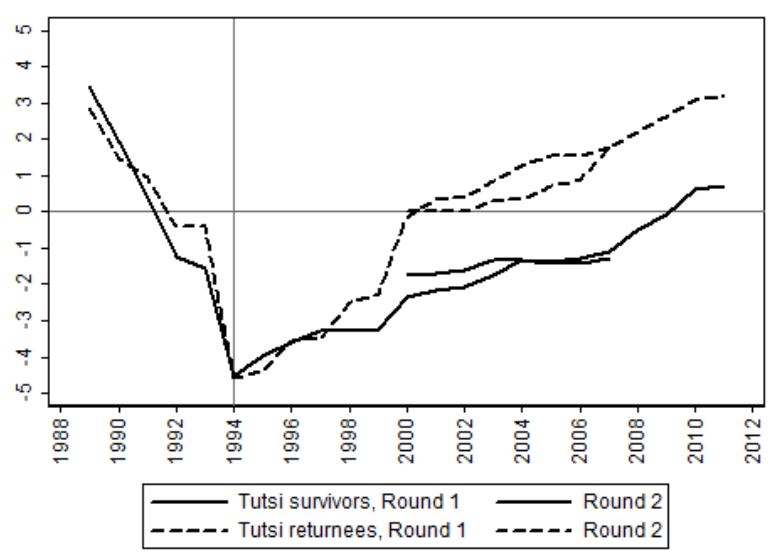

Panel B. Intra-ethnic trust

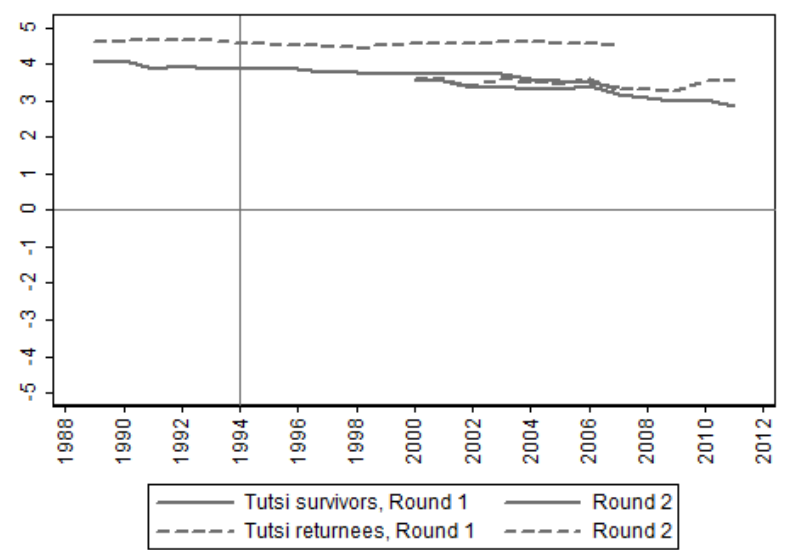

The data points in the figure rely on the subsample of the 412 respondents that could be traced across the two survey rounds.

Round 1 and round 2 data series are fully displayed, also for the overlapping period 2000-2007. 


\section{Replication of 'Figure 6. Inter-ethnic and Intra-ethnic trust, across Hutu subgroups' with full display of round 1 and round 2 data series}

Panel A. Inter-ethnic trust

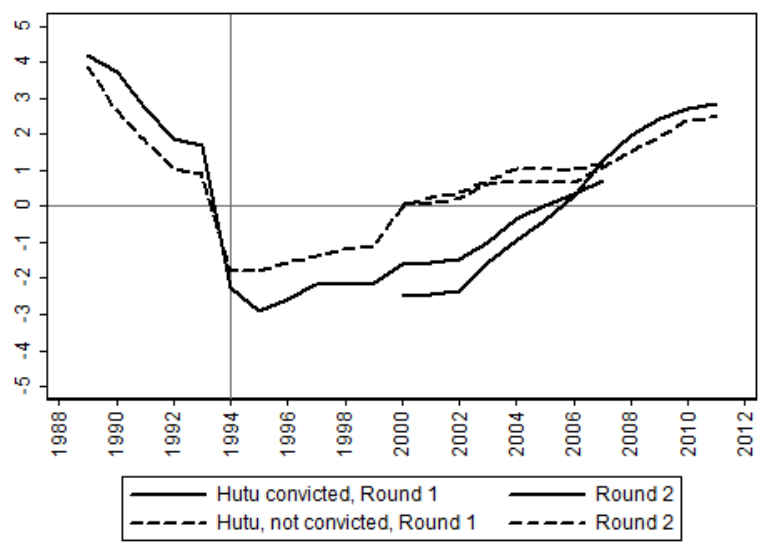

Panel B. Intra-ethnic trust

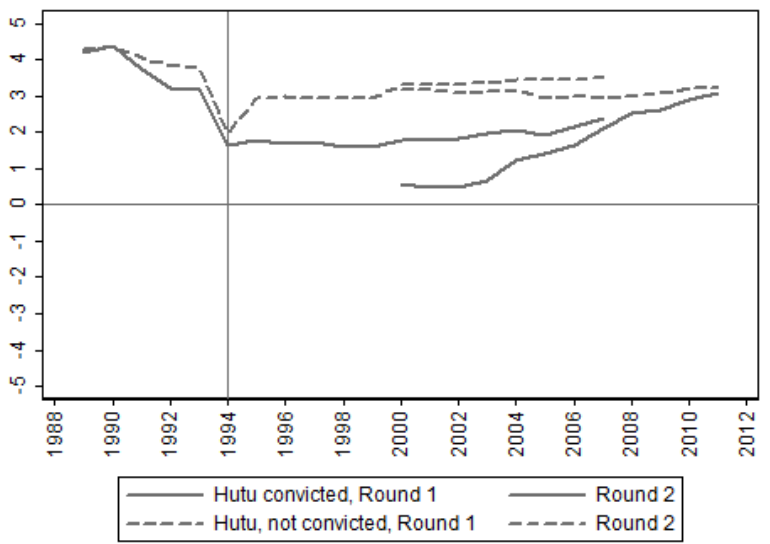

The data points in the figure rely on the subsample of the 412 respondents that could be traced across the two survey rounds.

Round 1 and round 2 data series are fully displayed, also for the overlapping period 2000-2007.

Replication of Table 2. Inter- and intra-ethnic trust in 1989, 2000, 2007 and 2011, and its change with respect to 1989

\begin{tabular}{|c|c|c|c|c|c|c|c|c|c|c|c|c|c|c|c|}
\hline & \multicolumn{8}{|c|}{ Levels } & \multicolumn{7}{|c|}{ Change with respect to 1989} \\
\hline & \multicolumn{5}{|c|}{ Round 1 data } & \multicolumn{4}{|c|}{ Round 2 data } & \multicolumn{3}{|c|}{ Round 1 data } & \multicolumn{3}{|c|}{ Round 2 data } \\
\hline & 1989 & & 1994 & & 2007 & 2007 & & 2011 & & 1994 & & 2007 & 2007 & & 2011 \\
\hline Inter-ethnic trust & 3.92 & & -1.71 & & 1.17 & 0.88 & & 2.37 & & -5.63 & ${ }^{* *}$ & $-2.75^{* *}$ & -3.04 & ** & -1.55 \\
\hline Intra-ethnic trust & 4.28 & & 1.85 & & 3.23 & 2.67 & & 2.99 & & -2.43 & ${ }^{* *}$ & $-1.05^{* *}$ & -1.61 & ** & -1.29 \\
\hline Difference & -0.36 & 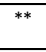 & -3.56 & ${ }^{* *}$ & $-2.06^{* *}$ & -1.79 & ${ }^{* *}$ & -0.62 & ${ }^{* *}$ & -3.20 & ${ }^{* *}$ & $-1.70^{* *}$ & -1.43 & ${ }^{* *}$ & -0.26 \\
\hline
\end{tabular}

${ }^{\dagger} \mathrm{p}<0.1,{ }^{*} \mathrm{p}<0.05,{ }^{* *} \mathrm{p}<0.01$. The numbers in the table are based on the subsample of 304 respondents for which there is a 1989 observation, and which could be traced in round 2 . 
Replication of Table 3. Inter-ethnic trust in 1989, 2000, 2007 and 2011, and its change with respect to 1989, across ethnic (sub)groups

\begin{tabular}{|c|c|c|c|c|c|c|c|c|c|c|c|c|c|c|c|}
\hline & \multicolumn{9}{|c|}{ Inter-ethnic trust } & \multicolumn{6}{|c|}{ Change with respect to 1989} \\
\hline & \multicolumn{6}{|c|}{ Round 1 data } & \multicolumn{4}{|c|}{ Round 2 data } & \multicolumn{2}{|c|}{ Round 1 data } & \multicolumn{3}{|c|}{ Round 2 data } \\
\hline & 1989 & & 1994 & & 2007 & & 2007 & & 2011 & & 1994 & 2007 & 2007 & 2011 & \\
\hline Tutsi & 3.29 & & -4.48 & & -0.45 & & -0.61 & & 1.11 & & $-7.77^{* *}$ & $-3.74^{* *}$ & $-3.90^{* *}$ & -2.18 & ** \\
\hline Hutu & 4.25 & & -0.30 & & 2.00 & & 1.65 & & 3.01 & & $-4.55^{* *}$ & $-2.25^{* *}$ & $-2.60^{* *}$ & -1.24 & ** \\
\hline Difference & -0.96 & *** & -4.18 & $* *$ & -2.45 & *** & -2.26 & *** & -1.90 & *** & $-3.22^{* *}$ & $-1.49^{* *}$ & $-1.30^{* *}$ & -0.94 & $*$ \\
\hline Tutsi - survivors & 3.47 & & -4.49 & & -1.26 & & -1.40 & & 0.33 & & $-7.96^{* *}$ & $-4.73^{* *}$ & $-4.87^{* *}$ & -3.14 & ** \\
\hline Tutsi - returnees & 2.87 & & -4.43 & & 1.53 & & 1.30 & & 3.00 & & $-7.30^{* *}$ & -1.34 & $-1.57^{\dagger}$ & 0.13 & \\
\hline Difference & 0.60 & & -0.06 & & -2.79 & ** & -2.70 & *** & -2.67 & $* *$ & -0.66 & $-3.39^{* *}$ & $-3.30^{* *}$ & -3.27 & ** \\
\hline Hutu - not convicted & 4.26 & & 0.27 & & 2.27 & & 1.66 & & 3.03 & & $-3.99^{* *}$ & $-1.99^{* *}$ & $-2.60^{* *}$ & -1.23 & ** \\
\hline Hutu - convicted & 4.20 & & -2.51 & & 0.95 & & 1.59 & & 2.93 & & $-6.71^{* *}$ & $-3.25^{* *}$ & $-2.61^{* *}$ & -1.27 & $* *$ \\
\hline Difference & 0.06 & & 2.78 & *** & 1.32 & *** & 0.07 & & 0.10 & * & $2.72^{* *}$ & $1.26^{*}$ & 0.01 & 0.04 & \\
\hline
\end{tabular}

${ }^{\dagger} \mathrm{p}<0.1,{ }^{*} \mathrm{p}<0.05,{ }^{* *} \mathrm{p}<0.01$. The numbers in the table are based on the subsample of 304 respondents for which there is a 1989 observation, and which could be traced in round 2.

Replication of Table 4. Intra-ethnic trust in 1989, 2000, 2007 and 2011, and its change with respect to 1989, across ethnic (sub)groups

\begin{tabular}{|c|c|c|c|c|c|c|c|c|c|c|c|}
\hline & \multicolumn{7}{|c|}{ Intra-ethnic trust } & \multicolumn{4}{|c|}{ Change with respect to 1989} \\
\hline & \multicolumn{5}{|c|}{ Round 1 data } & \multicolumn{2}{|c|}{ Round 2 data } & \multicolumn{2}{|c|}{ Round 1 data } & \multicolumn{2}{|c|}{ Round 2 data } \\
\hline & 1989 & 1994 & & 2007 & & 2007 & 2011 & 1994 & 2007 & 2007 & 2011 \\
\hline Tutsi & 4.21 & 3.91 & & 3.60 & & 2.92 & 2.74 & -0.30 & $-0.61^{* *}$ & $-1.29^{* *}$ & $-1.47^{* *}$ \\
\hline \multirow[b]{2}{*}{ Difference } & 4.31 & 0.80 & & 3.03 & & 2.54 & 3.12 & $-3.51^{* *}$ & $-1.28^{* *}$ & $-1.77^{* *}$ & $-1.19^{* *}$ \\
\hline & -0.10 & 3.11 & ${ }^{* *}$ & 0.57 & $*$ & 0.38 & -0.38 & $3.21^{* *}$ & $0.67^{* *}$ & 0.48 & -0.28 \\
\hline Tutsi - survivors & 4.05 & 3.71 & & 3.27 & & 2.90 & 2.52 & -0.34 & $-0.78^{*}$ & $-1.15^{* *}$ & $-1.53^{* *}$ \\
\hline Tutsi - returnees & 4.60 & 4.40 & & 4.40 & & 2.97 & 3.27 & -0.20 & -0.20 & $-1.63^{* *}$ & $-1.33^{* *}$ \\
\hline Difference & -0.55 & -0.69 & & -1.13 & $*$ & -0.07 & -0.75 & -0.14 & -0.58 & 0.48 & -0.20 \\
\hline Hutu - not convicted & 4.34 & 0.56 & & 3.21 & & 2.58 & 3.06 & $-3.78^{* *}$ & $-1.13^{* *}$ & $-1.76^{* *}$ & $-1.28^{* *}$ \\
\hline Hutu - convicted & 4.17 & 1.71 & & 2.34 & & 2.37 & 3.34 & $-2.46^{* *}$ & $-1.83^{* *}$ & $-1.80^{* *}$ & $-0.83^{* *}$ \\
\hline Difference & 0.17 & -1.15 & $*$ & 0.87 & ** & 0.21 & -0.28 & $-1.32^{*}$ & $0.70^{*}$ & 0.04 & -0.45 \\
\hline
\end{tabular}

${ }^{\dagger} \mathrm{p}<0.1,{ }^{*} \mathrm{p}<0.05,{ }^{* *} \mathrm{p}<0.01$. The numbers in the table are based on the subsample of 304 respondents for which there is a 1989 observation, and which could be traced in round 2 . 


\section{(iii) Full unbalanced panel}

In our baseline results we used the trust rankings of the 412 individuals that could be traced across round 1, that took place in 2007, and round 2, that took place in 2011. Furthermore, in the tables, where we compared trust rankings in 2000, 2007 and 2011 with respect to the baseline year 1989, we only included respondents whose life history covers the year 1989, so excluding the 108 (out of 412) respondents who started telling their life history from a later year (i.e. those who married/reached adulthood after 1989). Thus, for the tables, we remained with the rankings of 304 respondents.

In this robustness check, we show that our results remain when using each time the maximum sample size, i.e. the unbalanced panel including the rankings of 471 individuals for round 1 (where available), and 412 for the time series of round 2, and 304 for the life history year 1989, for which there is missing information on 125 (out of 471) respondents who started adulthood/marriage in later years.

\section{Replication of 'Figure 3. Inter- and Intra-ethnic trust, all respondents' with full unbalanced panel}

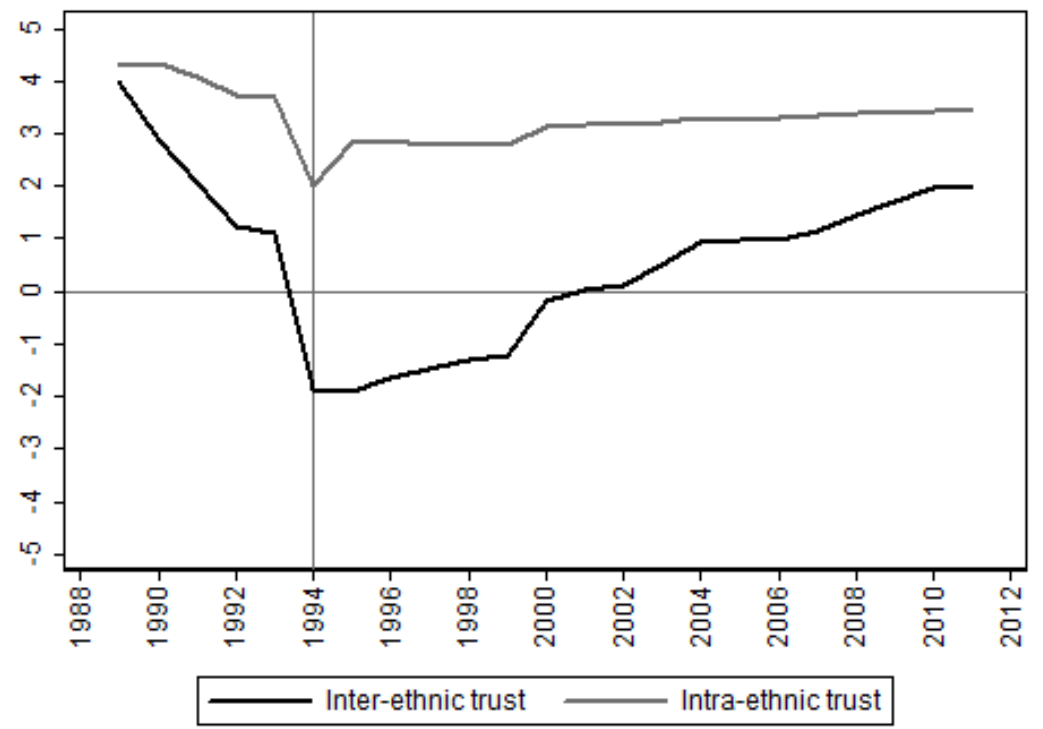

The data points in the figure rely on the full unbalanced panel of the 471 respondents. Round 1 data series are used for the overlapping period 2000-2007. Round 2 data series start from 2007 onwards. The round 2 series are shifted up- or downwards in order for the end point of round 1 to coincide with the starting point of round 2 . 


\section{Replication of 'Figure 4. Inter-ethnic and Intra-ethnic trust, Hutu vs. Tutsi' with full unbalanced panel}

Panel A. Inter-ethnic trust

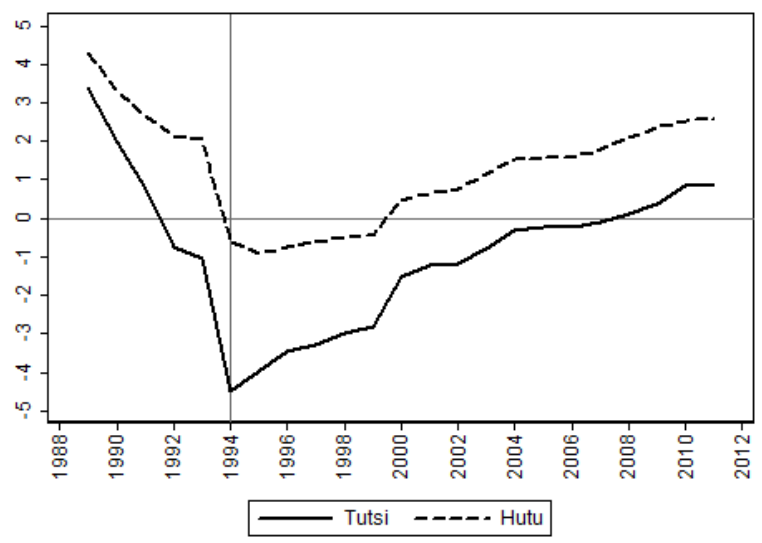

Panel B. Intra-ethnic trust

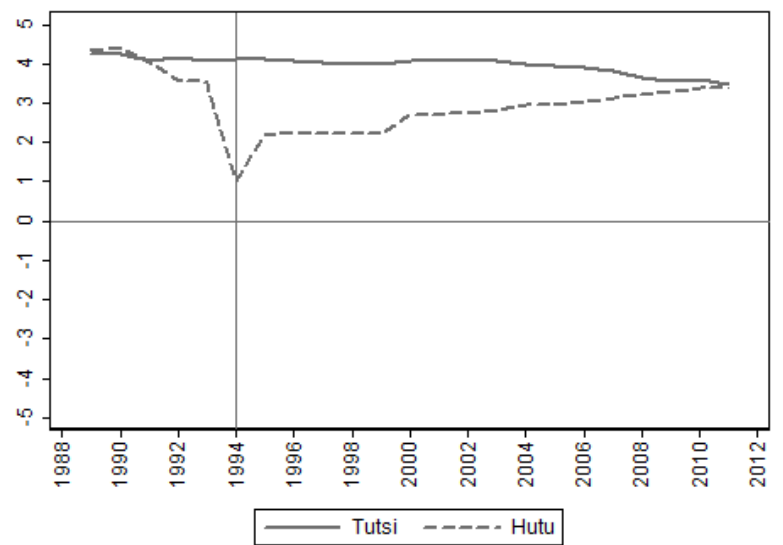

The data points in the figure rely on the full unbalanced panel of the 471 respondents. Round 1 data series are used for the overlapping period 2000-2007. Round 2 data series start from 2007 onwards. The round 2 series are shifted up- or downwards in order for the end point of round 1 to coincide with the starting point of round 2.

\section{Replication of 'Figure 5. Inter-ethnic and Intra-ethnic trust, across Tutsi subgroups' with full unbalanced panel}

Panel A. Inter-ethnic trust

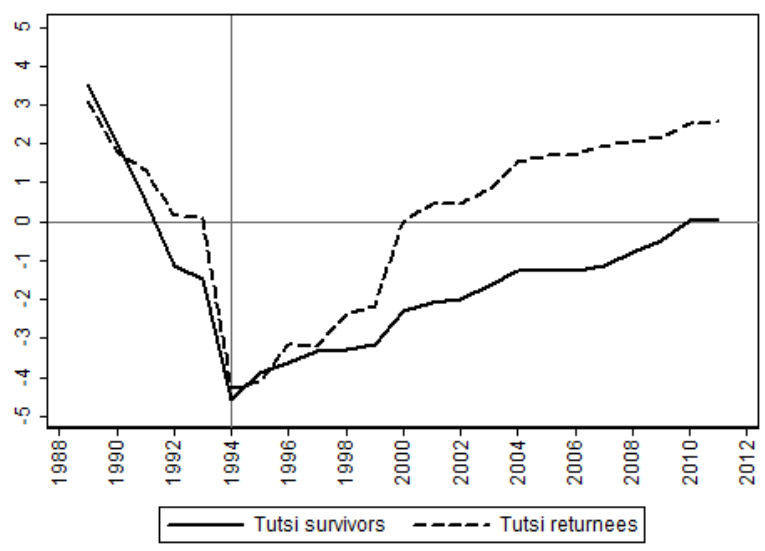

Panel B. Intra-ethnic trust

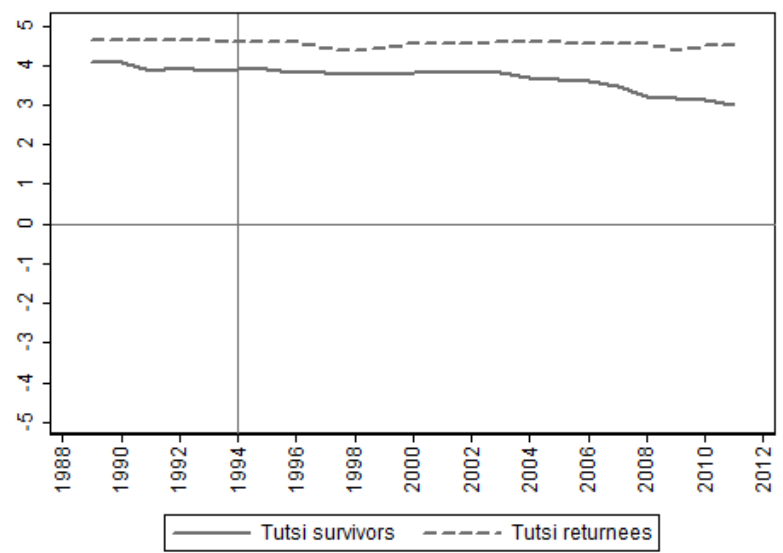

The data points in the figure rely on the full unbalanced panel of the 471 respondents. Round 1 data series are used for the overlapping period 2000-2007. Round 2 data series start from 2007 onwards. The round 2 series are shifted up- or downwards in order for the end point of round 1 to coincide with the starting point of round 2. 


\section{Replication of 'Figure 6. Inter-ethnic and Intra-ethnic trust, across Hutu subgroups' with full unbalanced panel}

Panel A. Inter-ethnic trust

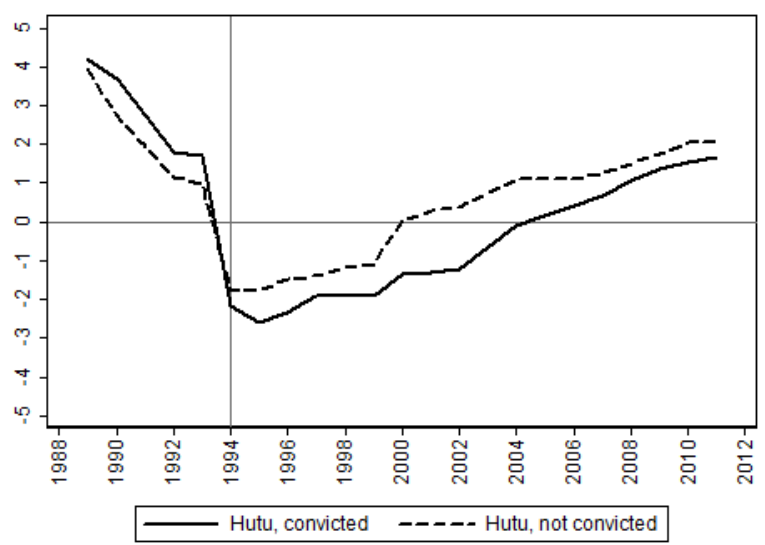

Panel B. Intra-ethnic trust

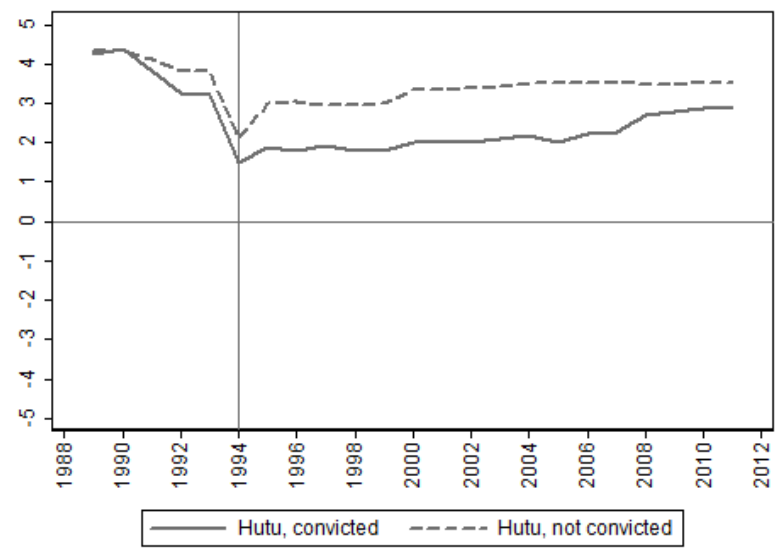

The data points in the figure rely on the full unbalanced panel of the 471 respondents. Round 1 data series are used for the overlapping period 2000-2007. Round 2 data series start from 2007 onwards. The round 2 series are shifted up- or downwards in order for the end point of round 1 to coincide with the starting point of round 2.

Replication of Table 2. Inter- and intra-ethnic trust in 1989, 2000, 2007 and 2011, and its change with respect to 1989

\begin{tabular}{ccccccccc}
\hline & \multicolumn{4}{c}{ Levels } & \multicolumn{4}{c}{ Change with respect to 1989} \\
& 1989 & 1994 & 2007 & 2011 & 1994 & 2007 & 2011 \\
\hline \hline Inter-ethnic trust & 3.99 & -1.72 & 1.18 & 2.11 & $-5.71^{* *}$ & $-2.81^{* *}$ & $-1.88^{* *}$ \\
Intra-ethnic trust & 4.31 & 1.88 & $3.23^{* *}$ & $3.27^{* *}$ & $-2.43^{* *}$ & $-1.08^{* *}$ & $-1.04^{* *}$ \\
\hline Difference & $-0.32^{* *}$ & $-3.60^{* *}$ & $-2.05^{* *}$ & $-1.16^{* *}$ & $-3.28^{* *}$ & $-1.73^{* *}$ & $-0.84^{* *}$ \\
\hline
\end{tabular}

${ }^{\dagger} \mathrm{p}<0.1,{ }^{*} \mathrm{p}<0.05,{ }^{* *} \mathrm{p}<0.01$. The numbers in the table are based on the subsample of 346 respondents for which there is a 1989 observation. For the overlapping period, 2000-2007, round 1 data are used. 
Replication of Table 3. Inter-ethnic trust in 1989, 2000, 2007 and 2011, and its change with respect to 1989, across ethnic (sub)groups

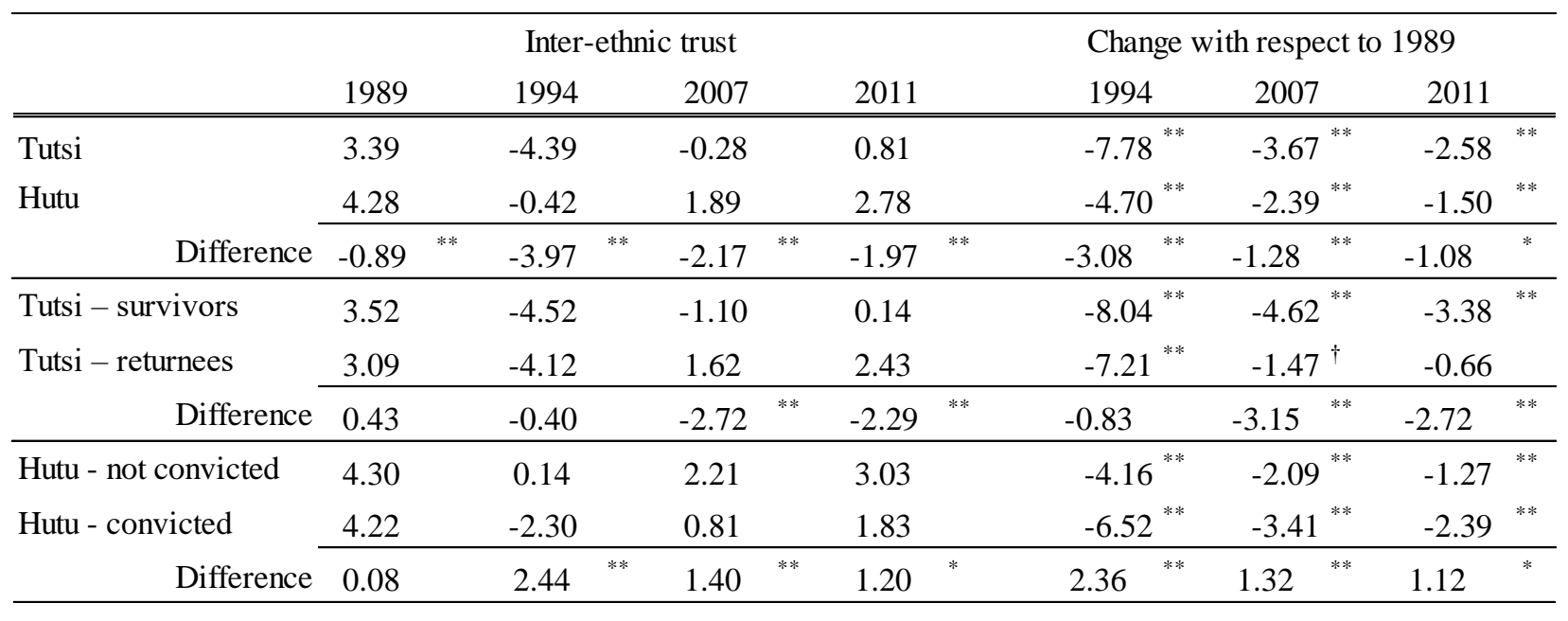

${ }^{\dagger} \mathrm{p}<0.1,{ }^{*} \mathrm{p}<0.05,{ }^{* *} \mathrm{p}<0.01$. The numbers in the table are based on the subsample of 346 respondents for which there is a 1989 observation. For the overlapping period, 2000-2007, round 1 data are used.

Replication of Table 4. Intra-ethnic trust in 1989, 2000, 2007 and 2011, and its change with respect to 1989, across ethnic (sub)groups

\begin{tabular}{|c|c|c|c|c|c|c|c|c|c|c|c|c|c|}
\hline & \multicolumn{7}{|c|}{ Intra-ethnic trust } & \multicolumn{6}{|c|}{ Change with respect to 1989} \\
\hline & 1989 & 1994 & & 2007 & & 2011 & & 1994 & & 2007 & & 2011 & \\
\hline Tutsi & 4.24 & 3.98 & & 3.68 & & 3.24 & & -0.26 & & -0.56 & ${ }^{* *}$ & -1.00 & ** \\
\hline \multirow[b]{2}{*}{ Difference } & 4.34 & 0.87 & & 3.00 & & 3.28 & & -3.47 & ${ }^{* *}$ & -1.34 & ${ }^{* *}$ & -1.06 & ${ }^{* *}$ \\
\hline & -0.10 & 3.11 & ** & 0.68 & ${ }^{* *}$ & -0.04 & & 3.21 & ${ }^{* *}$ & 0.78 & ** & 0.06 & \\
\hline Tutsi - survivors & 4.08 & 3.78 & & 3.37 & & 2.79 & & -0.30 & & -0.71 & ${ }^{*}$ & -1.29 & ** \\
\hline \multirow{2}{*}{$\begin{array}{l}\text { Tutsi - returnees } \\
\text { Difference }\end{array}$} & 4.62 & 4.44 & & 4.41 & & 4.33 & & -0.18 & & -0.21 & & -0.29 & \\
\hline & $-0.54^{\dagger}$ & -0.66 & & -1.04 & * & -1.54 & & -0.12 & & -0.50 & & -1.00 & + \\
\hline Hutu - not convicted & 4.37 & 0.69 & & 3.25 & & 3.40 & & -3.68 & ${ }^{* *}$ & -1.12 & ${ }^{* *}$ & -0.97 & ${ }^{* *}$ \\
\hline Hutu - convicted & 4.24 & 1.46 & & 2.22 & & 2.83 & & -2.78 & ${ }^{* *}$ & -2.02 & ${ }^{* *}$ & -1.41 & ** \\
\hline Difference & 0.13 & -0.77 & & 1.03 & ${ }^{* *}$ & 0.57 & $t$ & -0.90 & + & 0.90 & ${ }^{* *}$ & 0.44 & \\
\hline
\end{tabular}

${ }^{\dagger} \mathrm{p}<0.1,{ }^{*} \mathrm{p}<0.05,{ }^{* *} \mathrm{p}<0.01$. The numbers in the table are based on the subsample of 346 respondents for which there is a 1989 observation. For the overlapping period, 2000-2007, round 1 data are used. 


\section{A6. Alternative explanations}

We identified ethnic (sub)groups in terms of their roles in the genocidal violence (perpetrator- or victim- group) and their individual exposure to it (survivor vs returnee, and convicted vs nonconvicted), and we interpreted the changes in trust accordingly. But, the (sub)groups differ in other terms as well. In this Supplementary Appendix, we consider three broad categories of additional differentiations - (1) demographic characteristics, (2) post-genocide processes, and (3) other-than-genocidal violence - and study their implications on our results. 
First, the subgroups differ in terms of demographic characteristics; age and in particular gender. Table 6Ai shows that, in 2011, our respondents were on average 53 years old, and $37 \%$ were women. While there are no major age differences across subgroups, women are strongly overrepresented among Tutsi survivors (61\%) and not at all represented among convicted Hutu (0\%).

Table A6i. Age and sex across subgroups

\begin{tabular}{lcc}
\hline Subgroups & Female $(\%)$ & Age \\
\hline Tutsi- survivors & 0.61 & 52.0 \\
Tutsi - returnees & 0.49 & 57.7 \\
Hutu - not convicted & 0.34 & 53.4 \\
Hutu - convicted & 0.00 & 50.8 \\
\hline Average & 0.37 & 53.2 \\
\hline
\end{tabular}

Notes : Averages for the subsample of the 412 respondents that could be traced across the two survey rounds.

To verify whether our conclusions remain when controlling for age and gender, we turn to a regression analysis. In particular, we estimate the following equation:

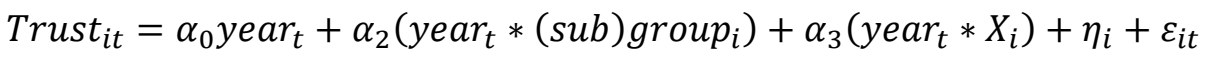

where $i$ indicates an individual respondent, $t$ indicates a year in the period 1989-2011, Trust $_{i t}$ stands for either inter-ethnic or intra-ethnic trust, $\eta_{i}$ are individual fixed effects ${ }^{13}$, and $\varepsilon_{i t}$ is the error term (clustered at the individual level to take into account that observations coming from the same subject are likely to be correlated). We control for the entire set of year dummies ${ }^{14}$, and interact them with an indicator variable for belonging to a particular (sub)group, as well as with the vector $X_{i}$ that includes the respondent's age and an indicator variable taking one for female respondents. The variable (sub)group $i$ corresponds alternatively to the Tutsi ethnic group (Table A6i'), the Tutsi survivor subgroup (Table A6i''), and the Hutu convicted subgroup (Table A6i','). In the latter two cases, we are interested in a within-group comparison and therefore restrict the analytical sample to ethnic Tutsi and Hutu, respectively. The results for inter-ethnic trust are displaced in panels A of the tables, while the results for intra-ethnic trust can be found in

\footnotetext{
${ }^{13}$ While the dependent variable in the econometric model is the level of trust, the model effectively analyses 'withinindividual' changes over time, due to the inclusion of individual fixed effects. The inclusion of individual fixed effects renders the inclusion of time-invariant individual characteristics (e.g. the variables Tutsi, or the vector X) superfluous.

14 The variable 'year' is a vector of dummy variables for each year comprised in our analysis, thus a series of 23 dummy variables for the years 1989 to 2011.
} 
panels B. The left column of each panel presents results of the baseline regression, i.e. the regression without the vector $X_{i}$. The results reveal that our conclusions about the differential trust trajectories across (sub)groups remain qualitatively similar.

Table A6i'. Regression analysis, Tutsi vs Hutu, controlling for interaction terms between year and female/age

\begin{tabular}{|c|c|c|c|c|}
\hline \multirow{3}{*}{ i.Year*Female } & \multicolumn{4}{|c|}{ Tutsi vs Hutu } \\
\hline & \multicolumn{2}{|c|}{ Inter-ethnic trust } & \multicolumn{2}{|c|}{ Intra-ethnic trust } \\
\hline & No & Yes & No & Yes \\
\hline i.Year*Age & No & Yes & No & Yes \\
\hline Tutsi*1990 & $-0.788 * *$ & -0.523 & -0.022 & 0.034 \\
\hline Tutsi*1991 & $-1.350 * * *$ & $-1.146^{* *}$ & 0.231 & 0.217 \\
\hline Tutsi*1992 & $-2.483 * * *$ & $-2.363 * * *$ & $0.707 * * *$ & $0.712 * * *$ \\
\hline Tutsi*1993 & $-2.584 * * *$ & $-2.483 * * *$ & $0.685^{* * * *}$ & $0.706 * * *$ \\
\hline Tutsi*1994 & $-3.355 * * *$ & $-3.448 * * *$ & $3.275 * * *$ & $3.599 * * *$ \\
\hline Tutsi*1995 & $-2.564 * * *$ & $-2.373 * * *$ & $2.089 * * *$ & $2.119 * * *$ \\
\hline Tutsi*1996 & $-2.216^{* * *}$ & $-1.952 * * *$ & $1.977 * * *$ & $2.011 * * *$ \\
\hline Tutsi*1997 & $-2.135 * * *$ & $-1.921 * * *$ & $1.938 * * *$ & $1.899 * * *$ \\
\hline Tutsi*1998 & $-1.930 * * *$ & $-1.761 * * *$ & $1.909 * * *$ & $1.869 * * *$ \\
\hline Tutsi*1999 & $-1.906 * * *$ & $-1.742 * * *$ & $1.901 * * *$ & $1.853 * * *$ \\
\hline Tutsi*2000 & $-1.487 * * *$ & $-1.365^{* * *}$ & $1.443 * * *$ & $1.422 * * *$ \\
\hline Tutsi*2001 & $-1.378^{* * *}$ & $-1.242 * * *$ & $1.410 * * *$ & $1.377 * * *$ \\
\hline Tutsi*2002 & $-1.445 * * *$ & $-1.302 * * *$ & $1.396^{* * *} *$ & $1.371 * * *$ \\
\hline Tutsi*2003 & $-1.407 * * *$ & $-1.211 * * *$ & $1.326^{* * * *}$ & $1.304 * * *$ \\
\hline Tutsi*2004 & $-1.357 * * *$ & $-1.103^{* *}$ & $1.103 * * *$ & $1.082 * * *$ \\
\hline Tutsi*2005 & $-1.380 * * *$ & $-1.097 * *$ & $1.031 * * *$ & $1.003 * * *$ \\
\hline Tutsi*2006 & $-1.395 * * *$ & $-1.059 * *$ & $0.924 * * *$ & $0.935 * * *$ \\
\hline Tutsi*2007 & $-1.441 * * *$ & $-1.044 * *$ & $0.669 * * *$ & $0.701 * * *$ \\
\hline Tutsi*2008 & $-1.313 * * *$ & $-0.929 *$ & $0.480^{*}$ & $0.534 * *$ \\
\hline Tutsi*2009 & $-1.307 * * *$ & $-0.921 *$ & 0.305 & 0.390 \\
\hline Tutsi*2010 & $-1.037 * *$ & -0.708 & 0.254 & 0.330 \\
\hline Tutsi*2011 & $-1.044 * *$ & -0.716 & 0.134 & 0.227 \\
\hline Constant & $3.786^{* * *}$ & $3.830 * * *$ & $4.412 * * *$ & $4.418 * * *$ \\
\hline Year FE & Yes & Yes & Yes & Yes \\
\hline Indivdiual FE & Yes & Yes & Yes & Yes \\
\hline Observations & 9,289 & 9,289 & 9,305 & 9,305 \\
\hline R-squared & 0.326 & 0.331 & 0.192 & 0.2 \\
\hline Number of id & 412 & 412 & 412 & 412 \\
\hline
\end{tabular}

${ }^{*} \mathrm{p}<0.1,{ }^{* *} \mathrm{p}<0.05,{ }^{* * *} \mathrm{p}<0.01$. Estimation of Eq. 1; the base categories are the year 1989, and the Hutu ethnic group; error terms clustered at the individual level. 
Table A6i". Regression analysis, Tutsi Survivors vs Tutsi Returnees, controlling for interaction terms between year and female/age

\begin{tabular}{|c|c|c|c|c|}
\hline \multirow[b]{3}{*}{ i.Year*Female } & \multicolumn{4}{|c|}{ Tutsi survivor vs Tutsi returnee } \\
\hline & \multicolumn{2}{|c|}{ Inter-ethnic trust } & \multicolumn{2}{|c|}{ Intra-ethnic trust } \\
\hline & No & Yes & No & Yes \\
\hline i.Year*Age & No & Yes & No & Yes \\
\hline Survivor*1990 & 0.172 & 0.549 & -0.068 & 0.063 \\
\hline Survivor*1991 & -0.833 & -0.472 & $-0.285^{*}$ & -0.168 \\
\hline Survivor*1992 & -1.124 & -0.610 & -0.209 & -0.061 \\
\hline Survivor*1993 & $-1.429^{*}$ & -0.898 & $-0.296^{*}$ & -0.153 \\
\hline Survivor*1994 & -0.204 & 0.261 & -0.141 & -0.043 \\
\hline Survivor*1995 & 0.106 & 0.735 & -0.059 & 0.111 \\
\hline Survivor*1996 & -0.326 & 0.161 & -0.111 & 0.070 \\
\hline Survivor*1997 & -0.070 & 0.421 & -0.142 & 0.039 \\
\hline Survivor*1998 & -1.058 & -0.669 & -0.108 & 0.081 \\
\hline Survivor*1999 & -1.237 & -0.860 & -0.240 & -0.072 \\
\hline Survivor*2000 & $-2.489 * * *$ & $-1.983^{* *}$ & -0.241 & -0.072 \\
\hline Survivor*2001 & $-2.796 * * *$ & $-2.318 * * *$ & -0.241 & -0.072 \\
\hline Survivor*2002 & $-2.732 * * *$ & $-2.276^{* * *}$ & -0.230 & -0.062 \\
\hline Survivor*2003 & $-2.855^{* * *}$ & $-2.353 * * *$ & -0.296 & -0.133 \\
\hline Survivor*2004 & $-2.901 * * *$ & $-2.315^{* * *}$ & -0.437 & -0.287 \\
\hline Survivor*2005 & $-3.221 * * *$ & $-2.668 * * *$ & -0.457 & -0.313 \\
\hline Survivor*2006 & $-3.243 * * *$ & $-2.697 * * *$ & -0.478 & -0.329 \\
\hline Survivor*2007 & $-3.336 * * *$ & $-2.820 * * *$ & $-0.584^{*}$ & -0.412 \\
\hline Survivor*2008 & $-3.152 * * *$ & $-2.642 * * *$ & $-0.757 * *$ & -0.561 \\
\hline Survivor*2009 & $-2.941 * * *$ & $-2.493 * * *$ & -0.633 & -0.430 \\
\hline Survivor*2010 & $-2.758 * * *$ & $-2.276 * * *$ & $-0.766^{* *}$ & -0.586 \\
\hline Survivor*2011 & $-2.759 * * *$ & $-2.268 * * *$ & $-0.916^{* *}$ & $-0.702^{*}$ \\
\hline Constant & $3.280^{* * *}$ & $3.294 * * *$ & $4.358 * * *$ & $4.308 * * *$ \\
\hline Year FE & Yes & Yes & Yes & Yes \\
\hline Indivdiual FE & Yes & Yes & Yes & Yes \\
\hline Observations & 3094 & 3094 & 3094 & 3094 \\
\hline R-squared & 0.419 & 0.442 & 0.041 & 0.061 \\
\hline Number of id & 138 & 138 & 138 & 138 \\
\hline
\end{tabular}

${ }^{*} \mathrm{p}<0.1,{ }^{* *} \mathrm{p}<0.05,{ }^{* * *} \mathrm{p}<0.01$. Estimation of Eq. 1; the analytical sample only includes ethnic Tutsi; the base categories are the year 1989, and the Tutsi returnees subgroup; error terms clustered at the individual level. 
Table A6i"', Regression analysis, Hutu Convicted vs Hutu Not-convicted, controlling for interaction terms between year and female/age

\begin{tabular}{|c|c|c|c|c|}
\hline \multirow[b]{3}{*}{ i.Year*Female } & \multicolumn{4}{|c|}{ Hutu convicted vs Hutu non-convicted } \\
\hline & \multicolumn{2}{|c|}{ Inter-ethnic trust } & \multicolumn{2}{|c|}{ Intra-ethnic trust } \\
\hline & No & Yes & No & Yes \\
\hline i.Year*Age & No & Yes & No & Yes \\
\hline Convicted*1990 & $0.549 *$ & 0.317 & 0.203 & 0.201 \\
\hline Convicted*1991 & 0.107 & -0.219 & -0.110 & -0.056 \\
\hline Convicted*1992 & -0.405 & -0.729 & -0.188 & -0.175 \\
\hline Convicted*1993 & -0.456 & -0.758 & -0.246 & -0.253 \\
\hline Convicted*1994 & $-2.180 * * *$ & $-2.094 * * *$ & $1.168^{* *}$ & $0.980^{*}$ \\
\hline Convicted*1995 & $-2.565 * * *$ & $-2.814 * * *$ & -0.185 & -0.045 \\
\hline Convicted*1996 & $-2.332 * * *$ & $-2.656 * * *$ & -0.361 & -0.230 \\
\hline Convicted*1997 & $-2.036 * * *$ & $-2.195^{* * *}$ & -0.262 & 0.035 \\
\hline Convicted*1998 & $-2.148 * * *$ & $-2.262 * * *$ & -0.471 & -0.172 \\
\hline Convicted*1999 & $-2.223 * * *$ & $-2.341 * * *$ & -0.480 & -0.184 \\
\hline Convicted $* 2000$ & $-2.623 * * *$ & $-2.645^{* * *}$ & $-0.865^{* *}$ & $-0.705^{*}$ \\
\hline Convicted*2001 & $-2.823 * * *$ & $-2.838 * * *$ & $-0.907 * *$ & $-0.727^{*}$ \\
\hline Convicted $* 2002$ & $-2.878 * * *$ & $-2.905 * * *$ & $-0.890 * *$ & $-0.713^{*}$ \\
\hline Convicted $* 2003$ & $-2.728 * * *$ & $-2.822 * * *$ & $-0.801 * *$ & -0.619 \\
\hline Convicted $* 2004$ & $-2.399 * * *$ & $-2.527 * * *$ & $-0.880 * *$ & $-0.749^{*}$ \\
\hline Convicted $* 2005$ & $-1.947 * * *$ & $-2.183 * * *$ & $-1.031 * *$ & $-0.908 * *$ \\
\hline Convicted $* 2006$ & $-1.615 * * *$ & $-1.914 * * *$ & $-0.853^{* *}$ & $-0.757^{*}$ \\
\hline Convicted*2007 & $-1.505^{* * *}$ & $-1.872 * * *$ & $-0.734 *$ & $-0.698^{*}$ \\
\hline Convicted $* 2008$ & $-1.407 * *$ & $-1.777 * * *$ & -0.439 & -0.406 \\
\hline Convicted $* 2009$ & $-1.350 * *$ & $-1.744 * * *$ & -0.453 & -0.444 \\
\hline Convicted $* 2010$ & $-1.324 * *$ & $-1.714 * * *$ & -0.415 & -0.399 \\
\hline Convicted*2011 & $-1.235^{* *}$ & $-1.637 * * *$ & -0.416 & -0.395 \\
\hline Constant & $4.016^{* * *}$ & $3.979 * * *$ & $4.436^{* * *}$ & $4.416 * * *$ \\
\hline Year FE & Yes & Yes & Yes & Yes \\
\hline Indivdiual FE & Yes & Yes & Yes & Yes \\
\hline Observations & 6,195 & 6,195 & 6,211 & 6,211 \\
\hline R-squared & 0.310 & 0.318 & 0.255 & 0.265 \\
\hline Number of id & 274 & 274 & 274 & 274 \\
\hline
\end{tabular}

${ }^{*} \mathrm{p}<0.1,{ }^{* *} \mathrm{p}<0.05,{ }^{* * *} \mathrm{p}<0.01$. Estimation of Eq. 1; the analytical sample only includes ethnic Hutu; the base categories are the year 1989, and the Hutu non-convicted subgroup; error terms clustered at the individual level. 
The (sub)groups also differ in terms of post-genocide processes, such as their perception of economic situation and political representation. Both these dimensions were systematically ranked by our respondents throughout their life history years. Figure A6ii shows the resulting trajectories, across subgroups.

\section{Figure A6ii. Economic situation and political representation as reported in life histories}

Panel A. Self-reported economic situation across time, by subgroup

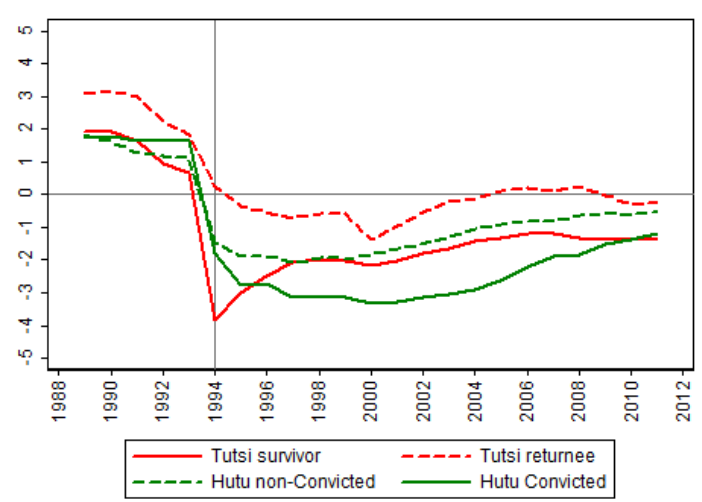

Panel B. Self-reported political representation across time, by subgroup

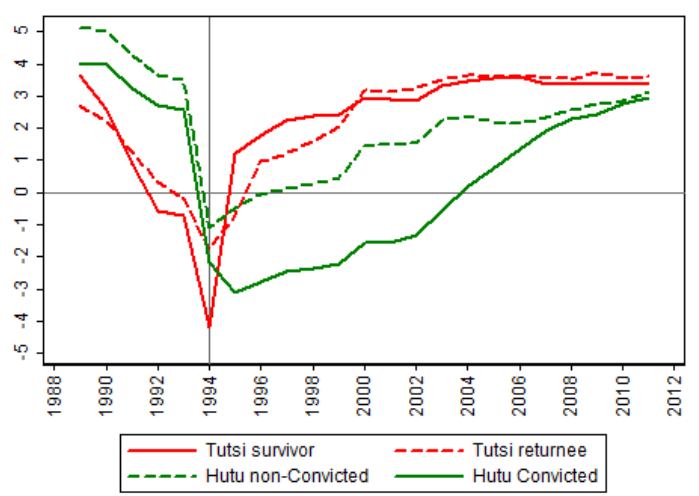

The data points in the figure rely on the subsample of the 412 respondents that could be traced across the two survey rounds. Round 1 data series are used for the overlapping period 2000-2007. Round 2 data series start from 2007 onwards. The round 2 series are shifted up- or downwards in order for the end point of round 1 to coincide with the starting point of round 2.

We verify whether controlling for these rankings knocks out our results on differential trust trajectories across the subgroups. To do so, we estimate the following equation:

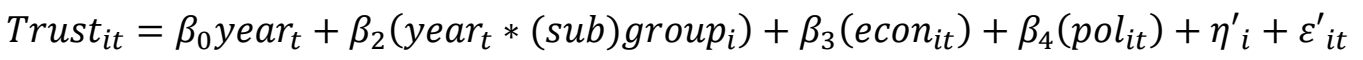

where variables and subscripts are defined as in Eq.1, and econ $i t$ and pol $_{i t}$ give the rankings of a respondent's perceived economic situation and political representation over time. Results are reported in Tables A6ii', A6ii', and A6ii','. We find that our results remain similar. 
Table A6ii'. Regression analysis, Tutsi vs Hutu, controlling for economic situation and political representation over time

\begin{tabular}{|c|c|c|c|c|}
\hline \multirow[b]{3}{*}{ Economic situation } & \multicolumn{4}{|c|}{ Tutsi vs Hutu } \\
\hline & \multicolumn{2}{|c|}{ Inter-ethnic trust } & \multicolumn{2}{|c|}{ Intra-ethnic trust } \\
\hline & no & $0.109 * * *$ & no & $0.051 * *$ \\
\hline Political representation & no & $0.259 * * *$ & no & $0.074 * * *$ \\
\hline Tutsi*1990 & $-0.788 * *$ & -0.578 & -0.022 & 0.027 \\
\hline Tutsi*1991 & $-1.350 * * *$ & $-0.976 * *$ & 0.231 & $0.324 * *$ \\
\hline Tutsi*1992 & $-2.483^{* * *}$ & $-1.843^{* * *}$ & $0.707 * * *$ & $0.895 * * *$ \\
\hline Tutsi*1993 & $-2.584 * * *$ & $-1.884 * * *$ & $0.685 * * *$ & $0.896^{* * *}$ \\
\hline Tutsi*1994 & $-3.355^{* * *}$ & $-3.060 * * *$ & $3.275 * * *$ & $3.393 * * *$ \\
\hline Tutsi*1995 & $-2.564 * * *$ & $-3.411 * * *$ & $2.089 * * *$ & $1.884 * * *$ \\
\hline Tutsi*1996 & $-2.216 * * *$ & $-3.176 * * *$ & $1.977 * * *$ & $1.728 * * *$ \\
\hline Tutsi*1997 & $-2.135 * * *$ & $-3.179 * * *$ & $1.938 * * *$ & $1.664 * * *$ \\
\hline Tutsi*1998 & $-1.930 * * *$ & $-2.972 * * *$ & $1.909 * * *$ & $1.650 * * *$ \\
\hline Tutsi*1999 & $-1.906^{* * *}$ & $-2.952 * * *$ & $1.901 * * *$ & $1.642 * * *$ \\
\hline Tutsi*2000 & $-1.487 * * *$ & $-2.433 * * *$ & $1.443 * * *$ & $1.203 * * *$ \\
\hline Tutsi*2001 & $-1.378 * * *$ & $-2.329 * * *$ & $1.410 * * *$ & $1.173 * * *$ \\
\hline Tutsi*2002 & $-1.445^{* * *}$ & $-2.397 * * *$ & $1.396 * * *$ & $1.155^{* * *}$ \\
\hline Tutsi*2003 & $-1.407 * * *$ & $-2.287 * * *$ & $1.326 * * *$ & $1.109 * * *$ \\
\hline Tutsi*2004 & $-1.357 * * *$ & $-2.199 * * *$ & $1.103 * * *$ & $0.897 * * *$ \\
\hline Tutsi*2005 & $-1.380 * * *$ & $-2.243 * * *$ & $1.031 * * *$ & $0.819 * * *$ \\
\hline Tutsi*2006 & $-1.395 * * *$ & $-2.239 * * *$ & $0.924 * * *$ & $0.717 * * *$ \\
\hline Tutsi*2007 & $-1.441 * * *$ & $-2.147 * * *$ & $0.669 * * *$ & $0.509 * *$ \\
\hline Tutsi*2008 & $-1.313 * * *$ & $-1.918 * * *$ & $0.480^{*}$ & 0.352 \\
\hline Tutsi*2009 & $-1.307 * * *$ & $-1.859 * * *$ & 0.305 & 0.198 \\
\hline Tutsi*2010 & $-1.037 * *$ & $-1.520 * * *$ & 0.254 & 0.166 \\
\hline Tutsi*2011 & $-1.044 * *$ & $-1.450 * * *$ & 0.134 & 0.070 \\
\hline Constant & $3.786^{* * * *}$ & $2.430 * * *$ & $4.412 * * *$ & $3.974 * * *$ \\
\hline Year FE & Yes & Yes & Yes & Yes \\
\hline Indivdiual FE & Yes & Yes & Yes & Yes \\
\hline Observations & 9,289 & 9,245 & 9,305 & 9,261 \\
\hline R-squared & 0.326 & 0.396 & 0.192 & 0.213 \\
\hline Number of id & 412 & 412 & 412 & 412 \\
\hline
\end{tabular}

${ }^{*} \mathrm{p}<0.1,{ }^{* *} \mathrm{p}<0.05,{ }^{* * *} \mathrm{p}<0.01$. Estimation of Eq. 2; the base categories are the year 1989, and the Hutu ethnic group; error terms clustered at the individual level. 
Table A6ii”. Regression analysis, Tutsi Survivors vs Tutsi Returnees, controlling for economic situation and political representation over time

\begin{tabular}{|c|c|c|c|c|}
\hline \multirow[b]{3}{*}{ Economic situation } & \multicolumn{4}{|c|}{ Tutsi survivor vs Tutsi returnee } \\
\hline & \multicolumn{2}{|c|}{ Inter-ethnic trust } & \multicolumn{2}{|c|}{ Intra-ethnic trust } \\
\hline & no & $0.215^{* * *}$ & no & 0.048 \\
\hline Political representation & no & $0.237 * * *$ & no & $0.068 * *$ \\
\hline Survivor*1990 & 0.172 & 0.373 & -0.068 & -0.052 \\
\hline Survivor*1991 & -0.833 & -0.545 & $-0.285^{*}$ & -0.245 \\
\hline Survivor*1992 & -1.124 & -0.785 & -0.209 & -0.159 \\
\hline Survivor*1993 & $-1.429 *$ & -1.263 & $-0.296^{*}$ & -0.293 \\
\hline Survivor*1994 & -0.204 & 1.172 & -0.141 & 0.135 \\
\hline Survivor*1995 & 0.106 & 0.167 & -0.059 & -0.118 \\
\hline Survivor*1996 & -0.326 & -0.124 & -0.111 & -0.138 \\
\hline Survivor*1997 & -0.070 & -0.036 & -0.142 & -0.243 \\
\hline Survivor*1998 & -1.058 & -1.059 & -0.108 & -0.260 \\
\hline Survivor*1999 & -1.237 & -1.143 & -0.240 & -0.366 \\
\hline Survivor*2000 & $-2.489 * * *$ & $-2.447 * * *$ & -0.241 & -0.327 \\
\hline Survivor*2001 & $-2.796^{* * *}$ & $-2.664 * * *$ & -0.241 & -0.318 \\
\hline Survivor*2002 & $-2.732 * * *$ & $-2.516 * * *$ & -0.230 & -0.285 \\
\hline Survivor*2003 & $-2.855 * * *$ & $-2.604 * * *$ & -0.296 & -0.355 \\
\hline Survivor*2004 & $-2.901 * * *$ & $-2.706^{* * *}$ & -0.437 & $-0.507 *$ \\
\hline Survivor*2005 & $-3.221 * * *$ & $-3.037 * * *$ & -0.457 & $-0.529 *$ \\
\hline Survivor*2006 & $-3.243 * * *$ & $-3.057 * * *$ & -0.478 & $-0.549 *$ \\
\hline Survivor*2007 & $-3.336 * * *$ & $-3.150 * * *$ & $-0.584 *$ & $-0.652 * *$ \\
\hline Survivor*2008 & $-3.152 * * *$ & $-2.924 * * *$ & $-0.757 * *$ & $-0.815^{* *}$ \\
\hline Survivor*2009 & $-2.941 * * *$ & $-2.706^{* * *}$ & -0.633 & $-0.682 *$ \\
\hline Survivor*2010 & $-2.758 * * *$ & $-2.637 * * *$ & $-0.766^{* *}$ & $-0.843 * *$ \\
\hline Survivor*2011 & $-2.759 * * *$ & $-2.628 * * *$ & $-0.916^{* *}$ & $-0.991 * * *$ \\
\hline Constant & $3.280 * * *$ & $1.955^{* * *} *$ & $4.358 * * *$ & $3.987 * * *$ \\
\hline Year FE & Yes & Yes & Yes & Yes \\
\hline Indivdiual FE & Yes & Yes & Yes & Yes \\
\hline Observations & 3,094 & 3,066 & 3,094 & 3,066 \\
\hline R-squared & 0.419 & 0.481 & 0.041 & 0.064 \\
\hline Number of id & 138 & 138 & 138 & 138 \\
\hline
\end{tabular}

${ }^{*} \mathrm{p}<0.1,{ }^{* *} \mathrm{p}<0.05,{ }^{* * *} \mathrm{p}<0.01$. Estimation of Eq. 2; the analytical sample only includes ethnic Tutsi; the base categories are the year 1989, and the Tutsi returnees subgroup; error terms clustered at the individual level. 
Table A6ii'", Regression analysis, Hutu Convicted vs Hutu Not-convicted, controlling economic situation and political representation over time

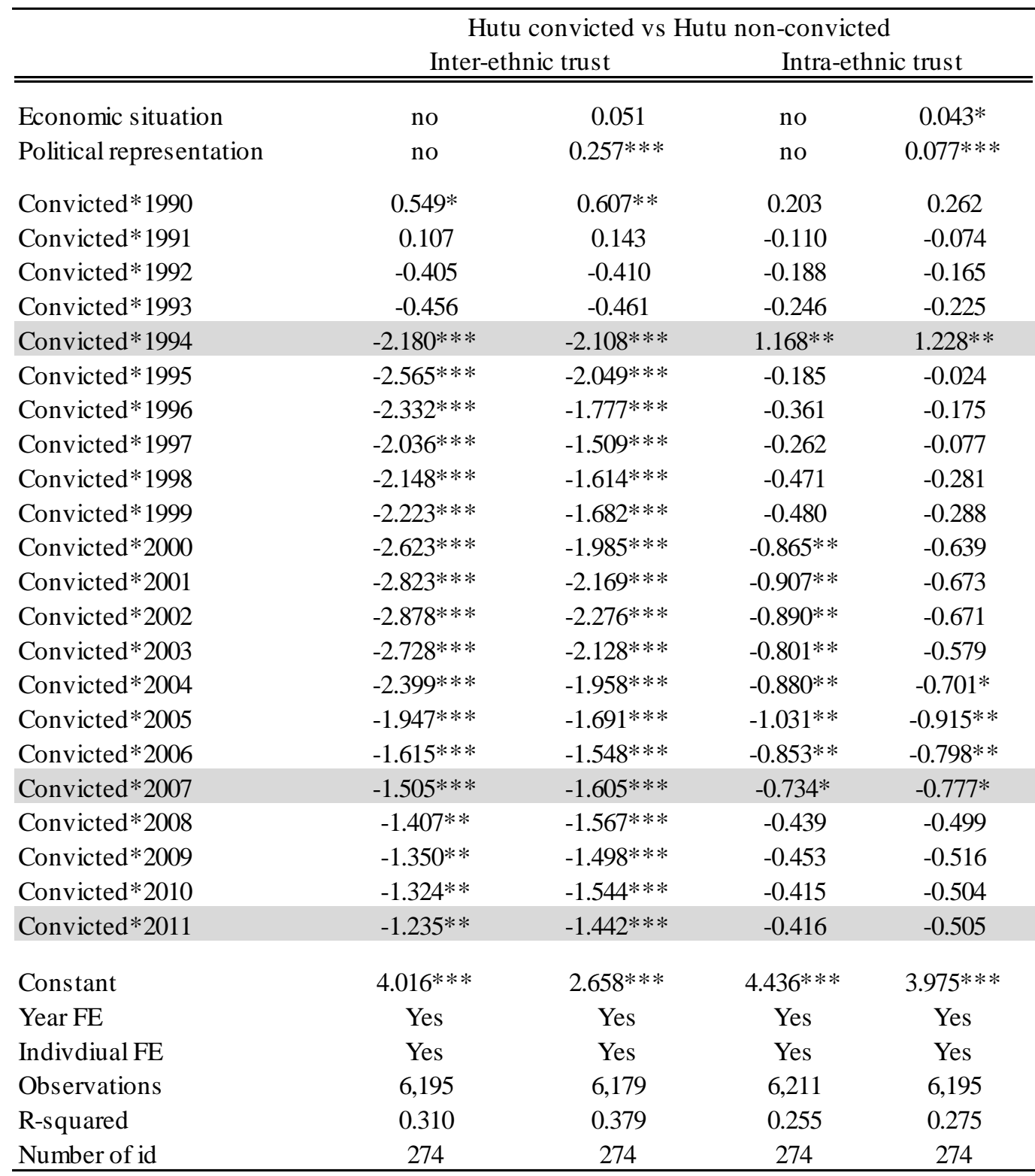

${ }^{*} \mathrm{p}<0.1,{ }^{* *} \mathrm{p}<0.05,{ }^{* * *} \mathrm{p}<0.01$. Estimation of Eq. 2; the analytical sample only includes ethnic Hutu; the base categories are the year 1989, and the Hutu non-convicted subgroup; error terms clustered at the individual level. 


\section{(iii) Other-than-genocidal violence}

Ethnic Hutu were not only the perpetrator group in the genocidal violence but they were also victims of other forms of violence including (civil or counterinsurgency) war, reprisal killings, and massacres by the RPF. We cannot systematically control for these forms of violence at the individual level. However, we tentatively explore whether these events confound our results, by exploiting their variation across our seven research localities.

Two research locations (Ruhengeri 1 and Ruhengeri 2) were affected by both the civil war and insurgency war; four research locations (Gitarama 2, Rural Kigali, Kibungo, and Ruhengeri) experienced revenge killings; and in three locations (Kibungo, Ruhengeri 1 and Ruhengeri 2) massacres committed by the RPF took place.

We estimate the following equation:

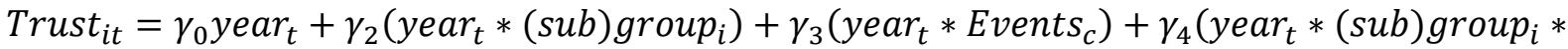
Events $\left._{c}\right)+\eta^{\prime \prime}{ }_{i}+\varepsilon^{\prime \prime}{ }_{i t}$

where variables and subscripts are defined as before, and Events $s_{c}$ is the sum of separate indicator variables for war, reprisal killings, and massacres, thus taking the values $0,1,2$ or 3 . Our coefficient of interest is $\gamma_{2}$. It captures the differential trust trajectories across (sub)groups in the absence of Events $_{c}$ in which Hutu were victimized, and thus provides us with a more appropriate test of our hypotheses in which we assume (convicted) Hutu to be the perpetrator group. Tables A6iii' and A6iii" show the results for the comparison of Hutu and Tutsi, and for the within-Hutu

comparison, respectively. ${ }^{15}$ Again, our results remain similar, except that, when only looking at places where Hutu were not victimized, we find even stronger recovery of inter-ethnic trust among Hutu, and in particular convicted Hutu. This suggests that victimization is a factor that slows down the recovery of inter-ethnic trust, also on the side of Hutu.

\footnotetext{
${ }^{15}$ We do not study the within-Tutsi comparison in this robustness check, as the modification to the estimating equation only has relevance for Hutu (the Tutsi civilian population was not a major complicit in these forms of violence).
} 
Table A6iii'. Regression analysis, Tutsi vs Hutu, making abstraction of locations in which Hutu were victimized

\begin{tabular}{|c|c|c|c|c|}
\hline & \multicolumn{4}{|c|}{ Tutsi vs Hutu } \\
\hline & \multicolumn{2}{|c|}{ Inter-ethnic trust } & \multicolumn{2}{|c|}{ Intra-ethnic trust } \\
\hline i.Year*Events & No & Yes & No & Yes \\
\hline i.Year*Events*Tutsi & No & Yes & No & Yes \\
\hline Tutsi*1990 & $-0.788 * *$ & $-1.074 * *$ & -0.022 & -0.228 \\
\hline Tutsi*1991 & $-1.350 * * *$ & $-1.642 * * *$ & 0.231 & -0.115 \\
\hline Tutsi*1992 & $-2.483 * * *$ & $-2.062 * * *$ & $0.707 * * *$ & $0.609 * *$ \\
\hline Tutsi*1993 & $-2.584 * * *$ & $-2.447 * * *$ & $0.685 * * *$ & 0.523 \\
\hline Tutsi*1994 & $-3.355^{* * *}$ & $-3.705 * * *$ & $3.275^{* * *}$ & $4.060 * * *$ \\
\hline Tutsi*1995 & $-2.564 * * *$ & $-2.837 * * *$ & $2.089 * * *$ & $2.798 * * *$ \\
\hline Tutsi*1996 & $-2.216^{* * *}$ & $-2.357 * * *$ & $1.977 * * *$ & $2.771 * * *$ \\
\hline Tutsi*1997 & $-2.135^{* * *}$ & $-2.227 * * *$ & $1.938 * * *$ & $2.361 * * *$ \\
\hline Tutsi*1998 & $-1.930 * * *$ & $-1.799 * * *$ & $1.909 * * *$ & $2.365^{* * *}$ \\
\hline Tutsi*1999 & $-1.906 * * *$ & $-1.830 * * *$ & $1.901 * * *$ & $2.317 * * *$ \\
\hline Tutsi*2000 & $-1.487 * * *$ & $-1.562 * *$ & $1.443 * * *$ & $1.912 * * *$ \\
\hline Tutsi*2001 & $-1.378 * * *$ & $-1.498 * *$ & $1.410 * * *$ & $1.891 * * *$ \\
\hline Tutsi*2002 & $-1.445^{* * *}$ & $-1.585^{* *}$ & $1.396^{* * *}$ & $1.908 * * *$ \\
\hline Tutsi*2003 & $-1.407 * * *$ & $-1.616^{* *}$ & $1.326 * * *$ & $1.799 * * *$ \\
\hline Tutsi*2004 & $-1.357 * * *$ & $-1.827 * * *$ & $1.103 * * *$ & $1.618 * * *$ \\
\hline Tutsi*2005 & $-1.380 * * *$ & $-1.687 * * *$ & $1.031 * * *$ & $1.444 * * *$ \\
\hline Tutsi*2006 & $-1.395 * * *$ & $-1.744 * * *$ & $0.924 * * *$ & $1.226 * * *$ \\
\hline Tutsi*2007 & $-1.441 * * *$ & $-2.024 * * *$ & $0.669 * * *$ & $1.118^{* *}$ \\
\hline Tutsi*2008 & $-1.313 * * *$ & $-2.027 * * *$ & $0.480 *$ & 0.693 \\
\hline Tutsi*2009 & $-1.307 * * *$ & $-2.271 * * *$ & 0.305 & 0.518 \\
\hline Tutsi*2010 & $-1.037 * *$ & $-1.877 * * *$ & 0.254 & 0.350 \\
\hline Tutsi*2011 & $-1.044^{* *}$ & $-1.917 * * *$ & 0.134 & 0.094 \\
\hline Constant & $3.786 * * *$ & $3.780 * * *$ & $4.412 * * *$ & $4.378^{* * *}$ \\
\hline Year FE & Yes & Yes & Yes & Yes \\
\hline Indivdiual FE & Yes & Yes & Yes & Yes \\
\hline Observations & 9,289 & 9,289 & 9,305 & 9,305 \\
\hline R-squared & 0.326 & 0.337 & 0.192 & 0.205 \\
\hline Number of id & 412 & 412 & 412 & 412 \\
\hline
\end{tabular}

${ }^{*} \mathrm{p}<0.1,{ }^{* *} \mathrm{p}<0.05,{ }^{* * *} \mathrm{p}<0.01$. Estimation of Eq. 3 ; the base categories are the year 1989, and the Hutu ethnic group; error terms clustered at the individual level. 
Table A6iii'”. Regression analysis, Hutu Convicted vs Hutu Not-convicted, making abstraction of locations in which Hutu were victimized

\begin{tabular}{|c|c|c|c|c|}
\hline & \multicolumn{4}{|c|}{ Hutu convicted vs Hutu non-convicted } \\
\hline & \multicolumn{2}{|c|}{ Inter-ethnic trust } & \multicolumn{2}{|c|}{ Intra-ethnic trust } \\
\hline i.Year*Events & No & Yes & No & Yes \\
\hline i.Year*Events*Convicted & No & No & No & No \\
\hline Convicted $* 1990$ & $0.549 *$ & 0.221 & 0.203 & -0.038 \\
\hline Convicted*1991 & 0.107 & 0.310 & -0.110 & -0.318 \\
\hline Convicted $* 1992$ & -0.405 & -0.582 & -0.188 & -0.582 \\
\hline Convicted $* 1993$ & -0.456 & -0.882 & -0.246 & -0.596 \\
\hline Convicted*1994 & $-2.180 * * *$ & $-3.130 * * *$ & $1.168 * *$ & $1.589 * *$ \\
\hline Convicted*1995 & $-2.565^{* * *}$ & $-3.617 * * *$ & -0.185 & -0.410 \\
\hline Convicted $* 1996$ & $-2.332 * * *$ & $-3.034 * * *$ & -0.361 & $-1.002 *$ \\
\hline Convicted $* 1997$ & $-2.036 * * *$ & $-2.959 * * *$ & -0.262 & $-1.343 * *$ \\
\hline Convicted $* 1998$ & $-2.148 * * *$ & $-3.036 * * *$ & -0.471 & $-1.163 * *$ \\
\hline Convicted $* 1999$ & $-2.223 * * *$ & $-3.034 * * *$ & -0.480 & $-1.187 * *$ \\
\hline Convicted $* 2000$ & $-2.623^{* * *}$ & $-2.223^{* * *} *$ & $-0.865^{* *}$ & $-1.173 * *$ \\
\hline Convicted $* 2001$ & $-2.823^{* * *}$ & $-2.286^{* * *}$ & $-0.907 * *$ & $-1.205^{* *}$ \\
\hline Convicted $* 2002$ & $-2.878 * * *$ & $-2.248 * * *$ & $-0.890 * *$ & $-1.141 * *$ \\
\hline Convicted $* 2003$ & $-2.728 * * *$ & $-1.890 * *$ & $-0.801 * *$ & $-1.073 * *$ \\
\hline Convicted $* 2004$ & $-2.399 * * *$ & $-1.460 *$ & $-0.880 * *$ & $-1.147 * *$ \\
\hline Convicted $* 2005$ & $-1.947 * * *$ & -1.266 & $-1.031 * *$ & $-1.938 * * *$ \\
\hline Convicted $* 2006$ & $-1.615 * * *$ & -0.702 & $-0.853^{* *}$ & $-1.541 * * *$ \\
\hline Convicted*2007 & $-1.505^{* * *}$ & -0.175 & $-0.734 *$ & $-1.197 * *$ \\
\hline Convicted $* 2008$ & $-1.407 * *$ & -0.239 & -0.439 & -0.697 \\
\hline Convicted $* 2009$ & $-1.350 * *$ & -0.405 & -0.453 & $-0.894 *$ \\
\hline Convicted $* 2010$ & $-1.324 * *$ & -0.271 & -0.415 & $-1.010 *$ \\
\hline Convicted $* 2011$ & $-1.235^{* *}$ & -0.206 & -0.416 & $-1.023^{*}$ \\
\hline Constant & $4.016 * * *$ & $4.039 * * *$ & $4.436^{* * *}$ & $4.395 * * *$ \\
\hline Year FE & Yes & Yes & Yes & Yes \\
\hline Indivdiual FE & Yes & Yes & Yes & Yes \\
\hline Observations & 6,195 & 6,195 & 6,211 & 6,211 \\
\hline R-squared & 0.310 & 0.328 & 0.255 & 0.274 \\
\hline Number of id & 274 & 274 & 274 & 274 \\
\hline
\end{tabular}

${ }^{*} \mathrm{p}<0.1,{ }^{* *} \mathrm{p}<0.05,{ }^{* * *} \mathrm{p}<0.01$. Estimation of Eq. 3; the analytical sample only includes ethnic Hutu; the base categories are the year 1989, and the Hutu non-convicted subgroup; error terms clustered at the individual level. 